\title{
Adult-Born Hippocampal Neurons Undergo Extended Development and Are Morphologically Distinct from Neonatally-Born Neurons
}

\author{
${ }^{D}$ John Darby Cole, ${ }^{*}$ Delane F. Espinueva, ${ }^{*}$ Désirée R. Seib, Alyssa M. Ash, ${ }^{\circledR}$ Matthew B. Cooke, \\ Shaina P. Cahill, Timothy P. O’Leary, Sharon S. Kwan, and J Jason S. Snyder \\ Department of Psychology, Djavad Mowafaghian Centre for Brain Health, University of British Columbia, Vancouver, British Columbia V6T 2B5, \\ Canada
}

During immature stages, adult-born neurons pass through critical periods for survival and plasticity. It is generally assumed that by 2 months of age adult-born neurons are mature and equivalent to the broader neuronal population, raising questions of how they might contribute to hippocampal function in old age when neurogenesis has declined. However, few have examined adult-born neurons beyond the critical period or directly compared them to neurons born in infancy. Here, we used a retrovirus to visualize functionally relevant morphological features of 2- to 24-week-old adult-born neurons in male rats. From 2 to 7 weeks, neurons grew and attained a relatively mature phenotype. However, several features of 7-week-old neurons suggested a later wave of growth: these neurons had larger nuclei, thicker dendrites, and more dendritic filopodia than all other groups. Indeed, between 7 and 24 weeks, adult-born neurons gained additional dendritic branches, formed a second primary dendrite, acquired more mushroom spines, and had enlarged mossy fiber presynaptic terminals. Compared with neonatal-born neurons, old adult-born neurons had greater spine density, larger presynaptic terminals, and more putative efferent filopodial contacts onto inhibitory neurons. By integrating rates of cell birth and growth across the life span, we estimate that adult neurogenesis ultimately produces half of the cells and the majority of spines in the dentate gyrus. Critically, protracted development contributes to the plasticity of the hippocampus through to the end of life, even after cell production declines. Persistent differences from neonatal-born neurons may additionally endow adult-born neurons with unique functions even after they have matured.

Key words: adult neurogenesis; aging; critical period; development; plasticity; retrovirus

Significance Statement

Neurogenesis occurs in the hippocampus throughout adult life and contributes to memory and emotion. It is generally assumed that new neurons have the greatest impact on behavior when they are immature and plastic. However, since neurogenesis declines dramatically with age, it is unclear how they might contribute to behavior later in life when cell proliferation has slowed. Here we find that newborn neurons mature over many months in rats and may end up with distinct morphological features compared with neurons born in infancy. Using a mathematical model, we estimate that a large fraction of neurons is added in adulthood. Moreover, their extended growth produces a reserve of plasticity that persists even after neurogenesis has declined to low rates.

Received July 12, 2019; revised Feb. 28, 2020; accepted May 4, 2020.

Author contributions: J.D.C., D.F.E., and J.S.S. designed research; J.D.C., D.F.E., D.R.S., A.M.A., M.B.C., S.P.C., T.P.O., S.S.K., and J.S.S. performed research; J.D.C., D.F.E., S.S.K., and J.S.S. analyzed data; J.S.S. wrote the paper.

*J.D.C. and D.F.E. contributed equally to this work.

This work was supported by the Natural Sciences and Engineering Research Council of Canada, the Canadian Institutes of Health Research, and the Michael Smith Foundation for Health Research.

The authors declare no competing financial interests.

Correspondence should be addressed to Jason S. Snyder at jasonsnyder@psych.ubc.ca.

https://doi.org/10.1523/JNEUROSCI.1665-19.2020

Copyright $\odot 2020$ the authors

\section{Introduction}

Morphological and physiological studies of adult-born dentate gyrus (DG) neurons suggest that adult neurogenesis may play an important role in hippocampal function. During the first 28 weeks of neuronal development, adult-born neurons are less constrained by GABAergic inhibition and display greater afferent and efferent synaptic potentiation (Snyder et al., 2001; Schmidt-Hieber et al., 2004; Ge et al., 2007; Gu et al., 2012; Marín-Burgin et al., 2012; Chancey et al., 2013). They have greater excitability, which enables them to be recruited despite immature innervation by cortical inputs (Mongiat et al., 2009; 
Dieni et al., 2013). During defined windows of time, they also undergo experience-dependent survival and innervation by excitatory and inhibitory neurons, and recruit GABAergic interneurons at higher rates (Epp et al., 2007; Tashiro et al., 2007; Anderson et al., 2010; Bergami et al., 2015; Vivar et al., 2015; Alvarez et al., 2016). The transient nature of these unique properties suggests that adult-born neurons have the greatest impact on circuits and behavior when they are in an immature critical period (Aimone et al., 2009; Kim et al., 2012; Snyder and Cameron, 2012).

While adult-born neurons eventually acquire features of developmentally born neurons (Laplagne et al., 2006; Stone et al., 2011), the extent to which they are similar is unclear because few studies have examined adult-born neurons beyond the traditional critical window of $\sim 2-6$ weeks. There is evidence that even old adult-born neurons have a unique capacity for experience-induced morphological growth and immediate early gene expression (Lemaire et al., 2012; Tronel et al., 2015). Additionally, studies that have characterized adult-born neurons at older ages typically have not directly compared them with neurons born in development, making it difficult to conclude whether adult-born neurons are fundamentally similar or distinct from developmentally born granule neurons. Work that has examined neurons born at different stages of life has found differences in the rate of maturation (Overstreet-Wadiche et al., 2006; Trinchero et al., 2017), neuronal survival (Dayer et al., 2003; Cahill et al., 2017; Ciric et al., 2019), immediate early gene expression (Imura et al., 2018; Ohline et al., 2018), and morphology and physiology (Kerloch et al., 2019; Save et al., 2019). Thus, there appears to be an ontogenetic basis for cellular heterogeneity in the DG (Snyder, 2019).

In most mammals, neurogenesis declines $\sim 90 \%$ between youth and mid-adulthood, and, by old age, newborn neurons are scarce (Lazic, 2012). If new neurons are particularly important during a brief window of immaturity, can neurogenesis make a significant contribution to hippocampal function later in life, when few neurons are added? This question is important because the DG is highly vulnerable to age-related pathology (Geinisman et al., 1986; Small et al., 2004; Yassa et al., 2010), and the extent of neurogenesis in human aging is unclear (Charvet and Finlay, 2018; Kempermann et al., 2018; Paredes et al., 2018; Snyder, 2019; Flor-García et al., 2020). One possibility is that adult-born (or later-born) neurons may continue to mature and display developmental plasticity beyond the traditional critical period. The fact that 4-monthold adult-born neurons display enhanced spatial learninginduced morphological plasticity (Lemaire et al., 2012) suggests that old adult-born neurons may still have "room to grow" later in life when fewer neurons are being generated. Second, protracted neurogenesis may contribute to the functional heterogeneity of the DG by producing distinct types of neurons at different stages of life (Snyder, 2019). In this way, neurons born in adulthood may mature to become distinct from neurons born in development, and may therefore offer unique functions even in old age, when neurogenesis rates have declined. To test these possibilities, we used a tdTomatoexpressing retrovirus to visualize the detailed morphology of DG neurons of various ages in rats. By examining dendrites, spines, and presynaptic terminals, we find that adult-born neurons continue to develop and become morphologically distinct from neonatal-born neurons over an extended period of 24 weeks.

\section{Materials and Methods}

\section{Animals}

Male Long-Evans rats were used in the following experiments. They were bred and housed in the animal facility of the Department of Psychology at the University of British Columbia (UBC) using wild-type breeders from Charles River Canada. All manipulations were conducted according to guidelines of the Canadian Council on Animal Care and with protocols approved by the UBC Animal Care Committee. Rats were weaned at $21 \mathrm{~d}$ of age, pair housed (cage size, $48 \times 27 \times 20 \mathrm{~cm}$ ) in male-only colony rooms that were separate from breeders, and given ad libitum access to water and rat chow. Cages were kept on a $12 \mathrm{~h}$ light/ dark cycle, with the light cycle starting at 9:00 A.M. All manipulations were conducted in the light phase.

\section{General experimental design}

An overview of the experimental design is provided in Figure 1. The general approach was to use a tdTomato-expressing retrovirus to birthdate cohorts of DG neurons that were either born in neonates (P1) or adults, and enable visualization and quantification of their morphological properties. To birthdate animals, pregnant dams were checked daily for litters and P1 was defined as the first day that pups were observed in the cage. Most groups were examined when rats were 16 weeks old; retrovirus was injected at different times before this end point to examine neurons at different stages of cellular development, and to compare them to neurons born in the neonatal period. Neuronal ages were 2 weeks (16 rats), 4 weeks ( 8 rats), 7 weeks (13 rats), and 16 weeks (15 rats; neonatalborn). An additional cohort of adult-born neurons was allowed to survive until 24 weeks ( 7 rats), and this was the only group in the main experiment that was examined at a different animal age ( 32 weeks). In a follow-up experiment, we injected groups of rats at 8 weeks of age $(n=4)$ or 14 weeks of age $(n=5)$ and examined cells 7 weeks later.

Some animals in the 2-, 4-, 7-, and 16-week-old neonatal groups were additionally trained for $1 \mathrm{~d}$ in a spatial water maze, 1 week before the end point, to examine possible experience-dependent effects on structural morphology. However, since the effects of water maze training were minimal, cells from control and trained rats were pooled for most analyses.

\section{Retrovirus production}

The retroviral vector used in this study was derived from a Moloney Murine Leukemia-Virus (MMLV), in which tdTomato expression is driven by a ubiquitin (Ubi) promoter, as described previously (van Praag et al., 2002). Retroviral Ubi-tdTomato (MMLV-tdTomato; provided by Shaoyu Ge; Stony Brook University, USA) and VSV-G (provided by Ana Martin-Villalba; German Cancer Research Center, Germany) plasmids were transfected in HEK293-GP cells (provided by Diane Lagace; University of Ottawa, Canada) using polyethylenimine. Retrovirus was harvested 2 and $3 \mathrm{~d}$ after transfection, followed by ultracentrifugation $(2 \mathrm{~h}$ at $89,527 \times g)$. Viral titers ranged from 0.8 to $30 \times 10^{4}$ colony-forming units $/ \mathrm{ml}$.

\section{Stereotaxic retrovirus injection into the dorsal dentate gyrus}

MMLV-tdTomato was injected into the DG of rats according to sterile surgical procedures approved by the UBC animal care committee. Rats were anaesthetized with isoflurane, given Ketoprofen $(5 \mathrm{mg} / \mathrm{kg})$, local bupivacaine, and lactated Ringer's solution $(10 \mathrm{ml} / \mathrm{kg})$ every hour during the surgery. For adult surgeries, heads were leveled and fixed in a stereotaxic frame (Kopf), and retrovirus injections were made at $-4.0 \mathrm{~mm}$ posterior, \pm 3.0 $\mathrm{mm}$ mediolateral, and $-3.5 \mathrm{~mm}$ ventral relative to bregma. One microliter of retrovirus was injected into each hemisphere, at a speed of $200 \mathrm{nl} / \mathrm{min}$, using a 30 gauge Hamilton needle and a microsyringe pump (World Precision Instruments). The needle remained in place for $5 \mathrm{~min}$ after the injection to allow the retrovirus to diffuse. For neonatal surgeries, pups were anesthetized with isoflurane, manually secured in the stereotaxic apparatus, and injected with $500 \mathrm{nl}$ of retrovirus into the dorsal hippocampus (position estimated by eye, relative to lambda) over $\sim 30 \mathrm{~s}$ (Mathon et al., 2015).

\section{Spatial water maze training}

Experimental and cage control animals from the 2-, 4-, 7-, and 16-weekold neonatal groups were habituated to handling for 1 week before the 
a

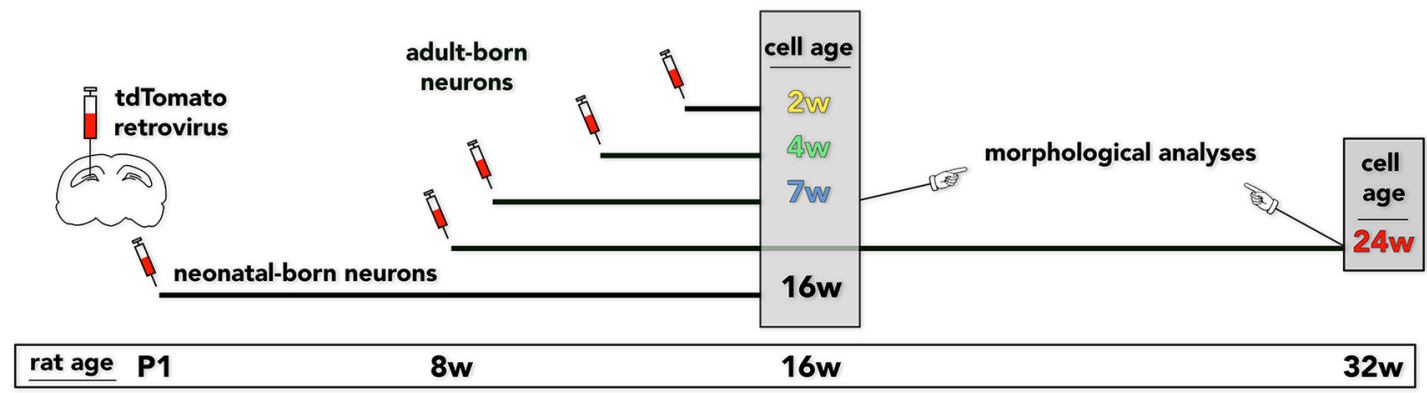

b

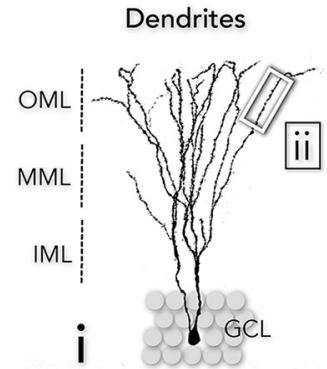

Dendrites

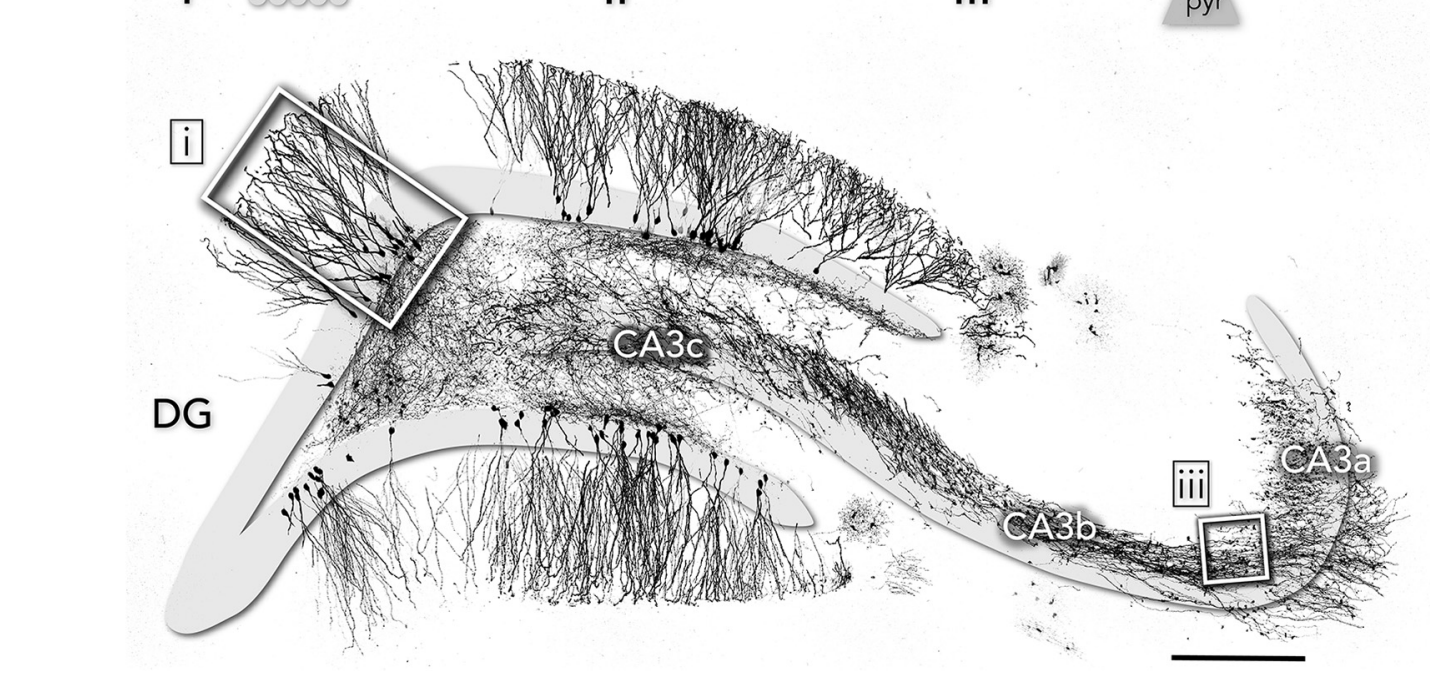

Presynaptic terminals

Postsynaptic spines
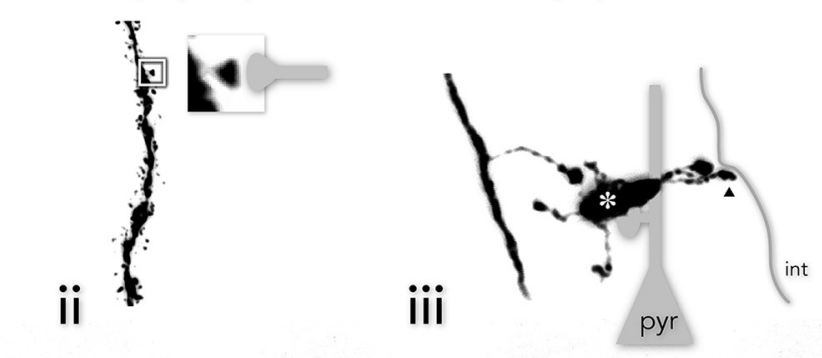

Figure 1. Experimental design. $\boldsymbol{a}$, Timeline: tdTomato-expressing retrovirus was injected into the DG of rats to birthdate granule neurons and visualize their morphological features. All groups were examined when rats were 16 weeks of age, except one cohort of adult-born cells that were allowed to mature for 24 weeks (rat age, 32 weeks) and a follow-up experiment that examined 7-week-old neurons born in 8- and 14-week-old rats (not shown here). $\boldsymbol{b}$, The large low-magnification confocal image shows retrovirally labeled, 24-week-old neurons in the dorsal hippocampus; granule and CA3 pyramidal cell layers were traced from DAPI ${ }^{+}$principal cell nuclei. Insets highlight the morphological features of DG neurons that were investigated: (1) dendritic trees; (2) spines; and (3) presynaptic mossy fiber boutons (*), which target CA3 pyramidal neurons (pyr), and filopodial terminals (arrowhead), which target inhibitory interneurons (int). OML, Outer molecular layer; MML, middle molecular layer; IML, inner molecular layer; GCL, granule cell layer. Scale bar, $500 \mu \mathrm{m}$. W, Week.

start of training. Trained rats were subjected to eight trials in a standard spatial water maze. The pool diameter was $2 \mathrm{~m}$, water temperature was $20^{\circ} \mathrm{C}$ and was made opaque with white nontoxic tempera paint, and the platform $(10 \mathrm{~cm}$ in diameter) was submerged $1 \mathrm{~cm}$ below the surface of the water. Distal 2D and 3D cues were located 1-3 $\mathrm{m}$ away, on the room walls, providing the spatial information needed to learn to navigate to the hidden platform.

\section{Tissue processing}

Animals were deeply anesthetized with isoflurane and transcardially perfused with $120 \mathrm{ml}$ of $4 \%$ paraformaldehyde (PFA) in PBS, pH 7.4. Extracted brains were immersed in $4 \%$ PFA for an additional $48 \mathrm{~h}$ at $4^{\circ} \mathrm{C}$ and then were transferred to PBS. Using a vibratome, brain sections were cut at $100 \mu \mathrm{m}$ and kept in their rostrocaudal sequence in 48-well plates to facilitate reconstruction of neurons across multiple sections. Slices were then incubated in $0.1 \mathrm{M}$ citric acid in a $99^{\circ} \mathrm{C}$ water bath for $15 \mathrm{~min}$, washed in PBS, and incubated in 10\% PBS-triton-x (TX) with 3\% horse serum (catalog \#16050122, Thermo Fisher Scientific) for
$30 \mathrm{~min}$. Sections were then incubated in rabbit anti-RFP (1:1000; catalog \#600401379, Rockland) with $10 \%$ PBS-TX with $3 \%$ horse serum for $72 \mathrm{~h}$ on a shaker at $4^{\circ} \mathrm{C}$. Sections were then washed with PBS-TX, incubated with donkey anti-rabbit Alexa-Fluor 555 (1:250; catalog \#A31572, Thermo Fisher Scientific) for $60 \mathrm{~min}$ at room temperature. After another PBS wash, slices were stained with DAPI (1:1000 in PBS) for $5 \mathrm{~min}$. Slices were washed with PBS four more times before being serially mounted onto slides (Fisherbrand Superfrost Plus Slides, Thermo Fisher Scientific) and coverslipped with PVA-DABCO.

Imaging and morphological analyses

For all morphological analyses, images of tdTomato ${ }^{+}$neurons in the dorsal DG $(-2.8 \mathrm{~mm}$ to $-4.8 \mathrm{~mm}$ relative to Bregma) were acquired with a Leica SP8 confocal microscope. Dendrite and spine analyses were restricted to the suprapyramidal blade, to avoid variation due to blade differences (Claiborne et al., 1990). All animals with successful bilateral or unilateral labeling were analyzed. While there was a range of viral titers, virus with lower and higher titers was distributed across groups 
and all animals within a given group had comparable tdTomato staining intensity. tdTomato immunostaining was sufficiently robust in all groups to enable reliable visualization and quantification, though staining intensity varied from cell to cell, and tended to be weaker in immature cells. To maintain approximate consistency across images, laser power and gain were adjusted to maintain a comparable dynamic range and to ensure that the brightness of the faintest spines was $\sim 25-30$, which was just visible by eye ( 8 bit images; range, $0-255$ ). To achieve this, the laser power ranged from $\sim 0.2$ to $3 \%$, and the gain ranged from $\sim 15$ to $60 \%$. Unless stated otherwise, analyses and measurements were performed on the $z$-stacks to accurately distinguish fine morphological details from each other and from background noise that can interfere with signals (e.g., particularly in maximum intensity projections).

For dendritic analyses, images $1024 \times 1024$ pixels in size and at a $z$ resolution of $1.25 \mu \mathrm{m}$ were acquired with a $25 \times$, water-immersion lens (numerical aperture, 0.95 ) at $1 \times$ zoom. Granule cells were imaged across adjacent sections to obtain the full dendritic tree. Neuronal dendrites were traced in ImageJ with the Simple Neurite Tracer plugin (Longair et al., 2011). The full dendritic tree (i.e., across multiple sections) was included for analyses of total dendritic length and dendritic branching order (e.g., $1^{\circ}, 2^{\circ}, 3^{\circ}$, using the Neuroanatomy plugins for ImageJ). Sholl analyses of dendritic branching were performed on individual sections that contained $\geq 70 \%$ of the total dendritic length of a given neuron (see details in Results). Dendrite thickness was measured from spine/protrusion images (see below) and was calculated as the average of three thickness measurements taken at both ends and the middle of the $30-70 \mu \mathrm{m}$ segment. A single segment was measured from each of the inner, middle, and outer molecular layers per cell.

Dendritic protrusion images were acquired with a glycerol-immersion $63 \times$ objective, at $1024 \times 1024$ pixels, $0.75 \mu \mathrm{m} z$-resolution, and $5 \times$ zoom. Segments $30-70 \mu \mathrm{m}$ in length, from cells in the suprapyramidal blade, were sampled from the inner, middle, and outer molecular layers (molecular layer divided into three zones of equal width, approximating the terminal zones for hilar, medial, entorhinal, and lateral entorhinal axons, respectively; Fig. 1b). Typically, the same neurons were sampled in all three layers, and, for total protrusion analyses, values were averaged. Protrusions, obvious elongations that extend approximately perpendicular from the dendrite, were counted with the ImageJ Cell Counter plugin. They were categorized according to the following morphological classes that vary with maturity (Toni et al., 2007; Berry and Nedivi, 2017): filopodia (immature, thin extensions that lack a bulbous head and are typically devoid of synapses); thin spines (putative postsynaptic spines that have a bulbous head and a thin neck); stubby spines (short and lacking a spine neck; spines with this appearance were included in protrusion density calculations but were not separately analyzed); and mushroom spines (mature, stable spines with synapses; here defined as those with a large head $\geq 0.6 \mu \mathrm{m}$ in diameter).

Large mossy fiber boutons (MFBs) were imaged with a glycerolimmersion $63 \times$ objective, at $1024 \times 1024$ pixels, $1 \mu \mathrm{m}$ z-resolution, and at $5 \times$ zoom. MFBs were sampled randomly within CA3a, CA3b, and $\mathrm{CA} 3 \mathrm{c}$, and were identified by their large, irregular shape and (typically) associated filopodial extensions (Claiborne et al., 1986; Acsády et al., 1998). A cross-sectional area was measured on maximum projections of stacked images using ImageJ. Filopodia, protrusions from the bouton between 1 and $25 \mu \mathrm{m}$ in length (Restivo et al., 2015), were analyzed from $z$-stacks.

Soma and nuclear sizes were measured from the neurons that were imaged for dendritic tree analyses, from the $z$-plane that had the largest tdTomato ${ }^{+}$cell body and associated $\mathrm{DAPI}^{+}$nucleus, respectively (typically the middle plane of the cell).

\section{Modeling neurogenic plasticity across the life span}

We developed a mathematical model to estimate the cumulative effects of neurogenesis throughout the life span, focusing on dendritic length and spine numbers. Using MATLAB, we identified functions that effectively fit age-related changes in neurogenesis and the growth of dendrites and spines as adult-born neurons matured. Peak DG neurogenesis was defined as 166,000 cells born on postnatal day 6 (P6; Schlessinger et al., 1975; Cahill et al., 2017), and rates of adult neurogenesis were estimated by scaling published ${ }^{3} \mathrm{H}-\mathrm{Thy}^{+}$and $\mathrm{BrdU}^{+}$cell counts (Altman and Das, 1965; Kuhn et al., 1996) relative to this peak, as we have done previously (Snyder, 2019). Neurogenesis rates were estimated by fitting a double Gaussian function to cell count data from P30 onward; only adult data (P56 onward) are included in the model. We did not correct for inflated counts due to redivision of labeled precursor cells for the following reasons: (1) embryonic and perinatal datasets were limited to heavily labeled granule neurons, thereby largely excluding cells that would be labeled due to redivision; (2) inflation due to redivision in adulthood will be approximately offset by the death of immature neurons [redivision causes a $\sim 2 \times$ increase in labeled cells (Cameron et al., 1993), and death removes approximately one-half of cells in rats (Snyder et al., 2009)]. The total (bilateral) granule cell population was fixed at 2.4 million cells (West et al., 1991), and one existing neuron (born before P56) was removed for each adult-born neuron that was added (Dayer et al., 2003; Cahill et al., 2017). For adult-born neurons, age-related increases in dendritic length and mushroom spines were fit with power functions, and total spines (thin + mushroom) were fit with a sigmoidal function. We then integrated dendrite and spine growth functions for all neurons born between P56 and P730 to predict morphological consequences of neurogenesis in adulthood (code: https://github.com/MatthewBCooke/ NeurogenesisFunctions). Dendrite lengths and spine densities for neurons born before adulthood were fixed at levels observed in P1-born neurons.

\section{Experimental design and statistical analyses}

Neuronal morphology varied substantially, even within the same animal. To retain these details and compare subpopulations of neurons of the same age, we performed most analyses at the level of the structure of interest (i.e., cell, bouton), except where indicated otherwise. In some instances, we also compared animal averaged data (e.g., to ensure that analyses were not skewed by overrepresentation of cells from an "outlier" animal). Morphological differences between neurons of different ages were typically assessed by standard or repeated-measures ANOVA with Holm-Sidak post hoc comparisons. Samples that were not normally distributed were log transformed before statistical analyses and, if distributions remained non-normal, the untransformed data were analyzed by a nonparametric Kruskal-Wallis test with post hoc comparisons by Dunn's test. All graphs show nontransformed data. Cells born in 8week-old versus 14-week-old animals were compared by two-tailed, unpaired $t$ tests except for branch order patterns, which were compared by repeated-measures ANOVA. Statistical analyses can be found in the main text for data that are not presented in the figures. For data that are presented in the figures, statistical analyses can be found in the Figure legends. The underlying data for all analyses are provided as Extended Data Figure 2-1. In all cases, significance was set at $\alpha=0.05$.

\section{Results}

\section{Water maze behavior}

The average latency to escape from the water maze decreased from $50 \mathrm{~s}$ on trials to 1 to $25 \mathrm{~s}$ on trial 8 , and there were no differences between groups (effect of trial, $F_{(7,322)}=8.8, p<0.0001$; effect of cell age group, $\left.F_{(3,46)}=1.5, p=0.22\right)$. The average path length taken to escape also decreased across trials $(1631 \mathrm{~cm}$ on trial 1 to $709 \mathrm{~cm}$ on trial 8) and was not different between groups (effect of trial, $F_{(7,322)}=11.7, p<0.0001$; effect of cell age group, $\left.F_{(3,46)}=1.8, p=0.16\right)$.

\section{Minor effects of water maze training on neuronal morphology}

Spatial water maze training over multiple days induces morphological and electrophysiological plasticity in adult-born neurons (Ambrogini et al., 2010; Tronel et al., 2010; Lemaire et al., 2012). Since the hippocampus is essential for remembering brief experiences (Feldman et al., 2010) and adult-born DG neurons show rapid changes in spine morphology following electrical 


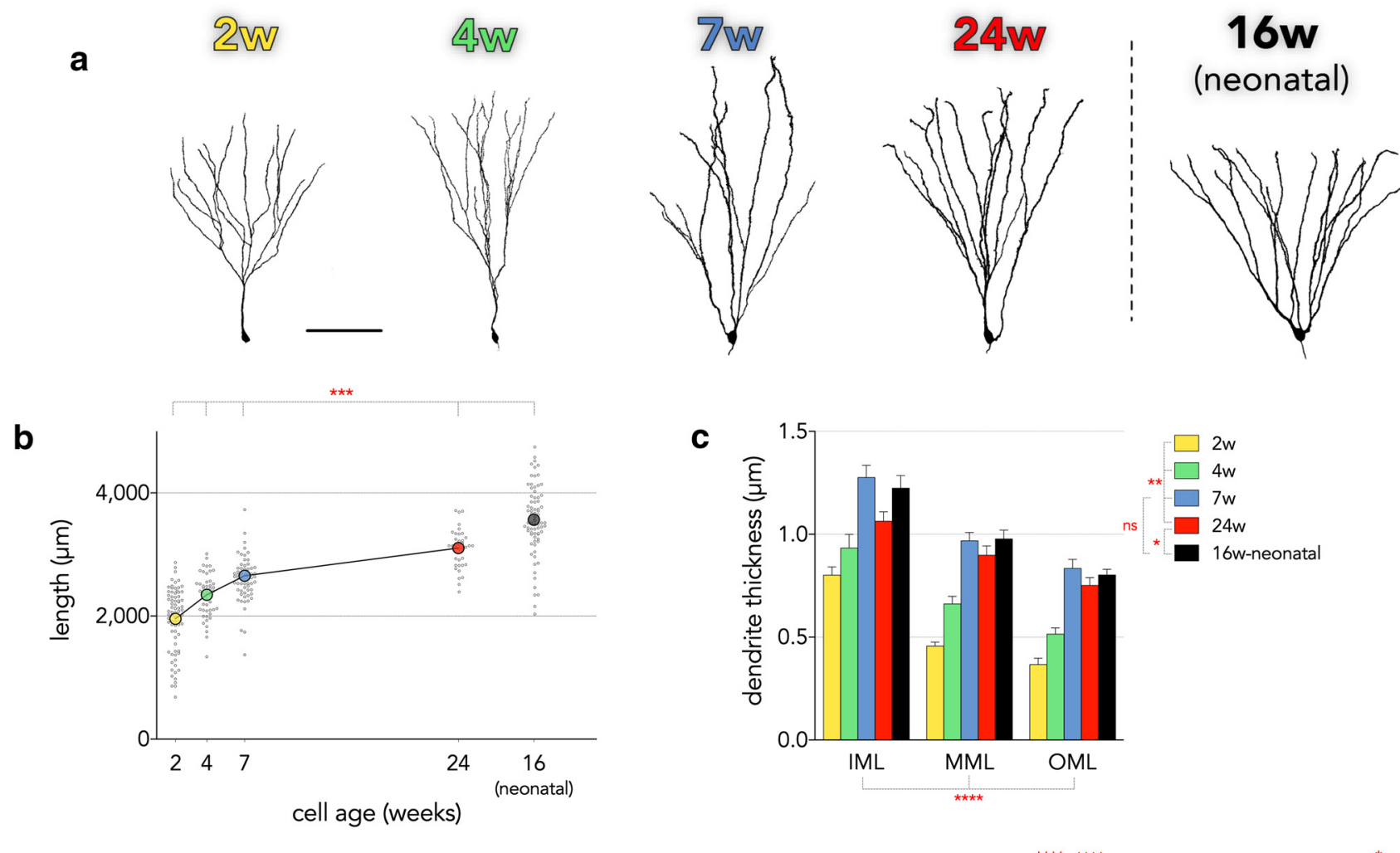

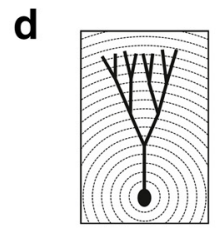

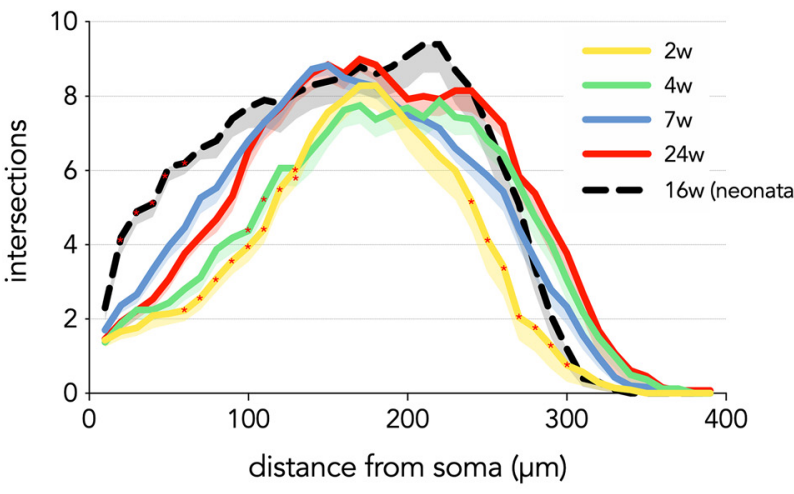

f

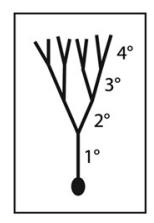

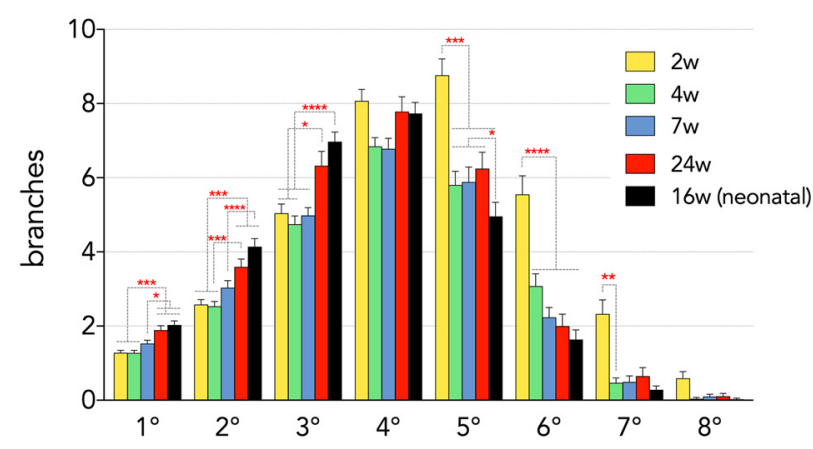

branch order

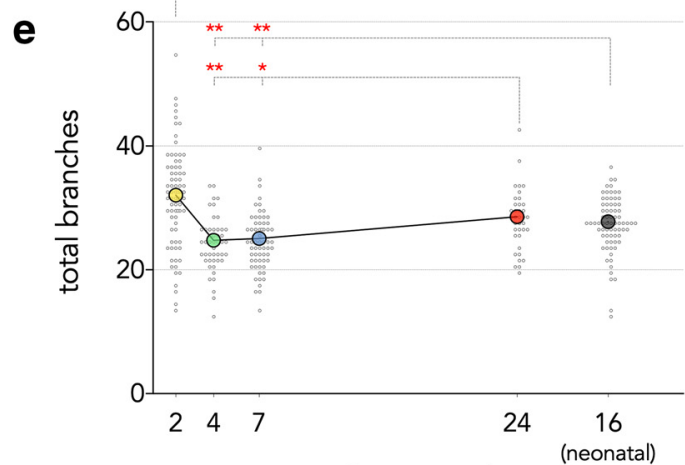

cell age (weeks)

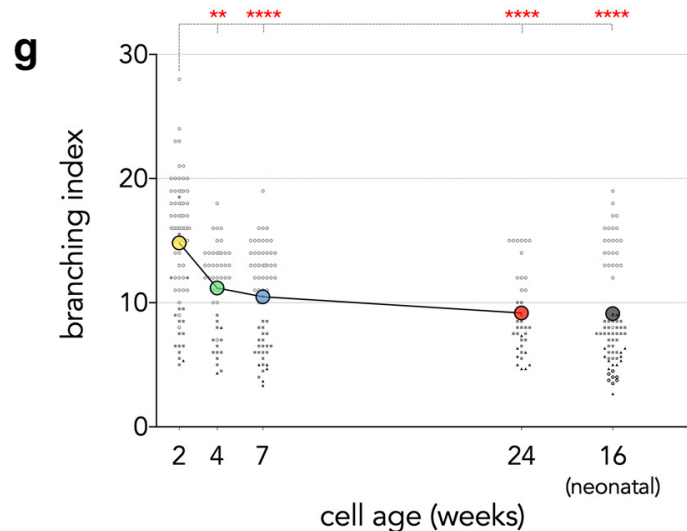

Figure 2. Dendritic structure of neonatal-born neurons and developing adult-born neurons. $\boldsymbol{a}$, Representative confocal images of fully reconstructed dendritic trees. Scale bar, $100 \mu \mathrm{m}$. Examples of trifurcating dendrites in Movie 1. Raw data are provided as Extended Data Figure 2-1. $\boldsymbol{b}$, The total dendritic length of adult-born neurons increased from 2 to 24 weeks and remained shorter than neonatal-born neurons $\left(F_{(4,296)}=120, p<0.0001\right.$; ${ }^{* *} p<0.001$ for all group comparisons). Colored symbols indicate group means, small gray circles indicate dendritic lengths of individual neurons. c, Dendrites became thicker with increasing adult-born neuron age, with the exception that 7-week-old cells had thicker dendrites than all adult-born groups, including 24-week-old cells. Neonatal-born cells had thicker dendrites than 24-week-old adult-born neurons. Dendrite thickness varied such that 0ML (outer molecular layer) $<$ MML (middle molecular layer) $<$ IML (inner molecular layer; repeated measures, mixed-effects model; effect of cell age: $F_{(4,260)}=52, p<0.0001$; effect of molecular layer region: $F_{(1.7,402)}=142$, 
stimulation (Ohkawa et al., 2012; Jungenitz et al., 2018), we hypothesized that a single session of water maze training may be sufficient to induce morphological plasticity in DG neurons. Contrary to our predictions, water maze training had minimal impact on the morphology of neonatal-born or adult-born neurons. These findings therefore do not contribute to the main conclusions of our study and, for our main analyses, data from trained and untrained rats are pooled. Nonetheless, we report the data from trained and untrained rats as follows: total dendritic length did not differ between control and water maze-trained rats (effect of training, $F_{(1,257)}=1.7, p=0.19$; training $\times$ cell age interaction, $\left.F_{(3,257)}=1.5, p=0.22\right)$.

Protrusion densities were greater in the inner molecular layer of water maze-trained rats but there was no difference between cell age groups (effect of training $\mathrm{F}_{1,237}=5.0, p=0.03$; training $\mathrm{x}$ cell age interaction, $\left.F_{(3,237)}=0.7, p=0.6\right)$. There was no effect of training on protrusion densities in the middle molecular layer or outer molecular layer (training effects, $p>0.25$; interactions, $p>0.08$ ). In the inner molecular layer, mushroom spine densities were greater in 7 -week-old cells in water maze-trained rats (effect of training, $F_{(1,237)}=2.8, p=0.1$; training $\times$ cell age interaction, $F_{(3,237)}=5.2, p=0.002 ; 7$-week-old cells in trained vs untrained rats, $p=0.002$ ). Water maze training increased mushroom spine densities in the middle molecular layer, but this was not different between cell age groups (effect of training, $F_{(1,235)}=$ 5.9, $p=0.02$; interaction, $\left.F_{(3,235)}=1.1 p=0.3\right)$. Water maze training did not significantly impact mushroom spine densities in the outer molecular layer (training and interaction effects, both $p>0.6)$.

Water maze training did not alter MFB size in CA3a or CA3b (training and interaction effects, all $p>0.07$ ). In CA3c, MFBs were smaller in 2-week-old cells in water maze-trained rats (cell age $\times$ training interaction, $F_{(3,195)}=2.9, p=0.03$; MFBs in trained vs untrained rats, $p=0.006)$. Water maze training did not alter the number of filopodia/MFBs, or the length of filopodia,

\footnotetext{
$\leftarrow$

$p<0.0001$; cell $\times$ layer interaction: $\left.F_{(8,477)}=0.9, p=0.5\right)$. $\boldsymbol{d}$, Sholl analyses revealed distinct patterns of dendritic complexity across cell ages (effect of cell age: $F_{(4,85)}=16$, $p<0.0001$; cell age $\times$ dendritic subregion interaction: $F_{(116,2465)}=2.9, p<0.0001 ; 10-$ $300 \mu \mathrm{m}$ analyzed since cells did not reliably extend beyond $300 \mu \mathrm{m}$ in all groups). The total number of intersections was different between all groups (all comparisons, $p<0.05$ ). Twoweek-old neurons had fewer intersections than older adult-born neurons in both proximal and distal dendritic regions $\left(60-130 \mu \mathrm{m},{ }^{*} p<0.05\right.$ vs 7 - and 24-week-old cells; $240-$ $300 \mu \mathrm{m},{ }^{*} p<0.05$ vs 24 -week-old cells). Neonatal-born neurons had more intersections in proximal dendritic regions (20-60 $\mu \mathrm{m},{ }^{*} p<0.05$ vs all other groups). Four-week-old neurons had fewer intersections than 7- and 24-week-old neurons at 100, 110, and $130 \mu \mathrm{m}$ $\left({ }^{*} p<0.05\right)$. Lines connect mean values (not shown), shading indicates the SEM. $\boldsymbol{e}$, Twoweek-old adult-born neurons had more dendritic branches than all other groups except 24week-old cells. After initial pruning from 2 to 4 weeks, the number of branches increased from 7 to 24 weeks (Kruskal-Wallis test, $p<0.0001$ followed by Dunn's post-test). Symbols as in $\boldsymbol{b}$. $\boldsymbol{f}$, Dendritic branching varied as a function of branch order and cell age (effect of cell age: $F_{(4,1682)}=7.1, p<0.0001$; effect of dendrite order: $F_{(7,1682)}=394.1, p<0.0001$; interaction: $\left.F_{(28,1682)}=9.0, p<0.0001\right)$. Neonatal-born neurons and 24-week-old adult-born neurons had more lower-order branches than 2- to 7-week-old adult-born neurons. In contrast, young adult-born neurons (particularly 2 weeks old) had more high-order branches. Bars indicate the mean \pm SEM. $\boldsymbol{g}$, The branching index (branch tips/number of primary dendrites) was greater in 2-week-old cells than all other cell ages (Kruskal-Wallis test, $p<0.0001$ ). White circles, gray squares, black triangles, and gray circles indicate cells with one, two, three, and four primary dendrites, respectively. The branching index was also greater in 2-week-old cells than in other adult-born cells when only single primary dendrite cells were analyzed (Kruskal-Wallis test, $p<0.0001$; 2- vs 4 - and 7-week-old cells, $p<0.0001 ; 2$ - vs 24-week-old cells, $p=0.02 ; 2$ - vs 16-week-old neonatal cells, $p=0.4$ ). ${ }^{*} p<0.05,{ }^{* *} p<0.01,{ }^{* * *} p<0.001,{ }^{* * * *} p<0.0001$. w, Week.
}

in any CA3 subregion (training and interaction effects, all $p>0.11)$.

\section{Dendrites}

Consistent with previous reports, the dendritic tree of adult-born neurons matured over several weeks (Fig. 2). The 2- and 4-weekold neurons had noticeably thinner and more irregularly shaped dendrites that often did not extend to the hippocampal fissure. By 7 weeks, dendrites were thicker and longer, and at even older ages, the tips of dendrites often curved sideways on approaching the hippocampal fissure. While less common than in younger cells, early-terminating dendrites (Fig. 2a) and thin, spine-poor dendritic segments (see Fig. $4 a$ ) were also observed on 7- and 24week-old neurons, suggesting the presence of immature processes and continued growth.

To determine the time frame of growth of adult-born neuron dendrites, dendritic lengths were measured in their entirety, across sections. The total number of cells examined were as follows: 76 (2 weeks), 49 (4 weeks), 65 (7 weeks), 37 (24 weeks), 74 [16 weeks (neonatal)]. Among adult-born cells, dendritic length increased from $1954 \mu \mathrm{m}$ at 2 weeks to $3105 \mu \mathrm{m}$ at 24 weeks (Fig. $2 b$ ). There was greater dendritic growth at younger cell ages; from 2 to 4 weeks, there was a net increase of $392 \mu \mathrm{m}(28 \mu \mathrm{m} / \mathrm{d})$, whereas over the much longer interval of 4-24 weeks there was only an additional $759 \mu \mathrm{m}$ of growth $(4 \mu \mathrm{m} / \mathrm{d})$. Neonatal-born neurons had an average total dendritic length of $3565 \mu \mathrm{m}$; this was greater than all adult-born neuron groups, although populations overlapped.

Group means that were calculated from animal-averaged data differed by $<1 \%$ from means that were calculated by pooling all cells of a given age category. The same pattern of group differences was also observed when groups were composed of animal averaged data rather than individual cell data $\left(\mathrm{F}_{(4,55)}=57\right.$, all cell ages significantly different from one another: $0.05>p>0.0001)$.

As an additional index of dendritic growth, we measured the width of dendrites in the inner, middle, and outer molecular layers (Fig. 2c). Dendrite thickness doubled between 2 and 7 weeks $(0.5-1.0 \mu \mathrm{m})$ and then decreased slightly by 24 weeks, which was thinner than 16-week-old neonatal neurons. Consistent with theoretical predictions that dendrites taper to optimize current transfer (Bird and Cuntz, 2016), dendritic thickness decreased from the inner to middle to outer molecular layers, and this did not vary across cell age.

Dendritic branching patterns change as adult-born neurons develop (Kerloch et al., 2019), and their precise morphology likely determines the strength and integration of synaptic inputs from different pathways (Spruston, 2008). We therefore conducted a Sholl analysis and quantified the number of dendritic intersections at concentric $10 \mu \mathrm{m}$ intervals from the cell body through the molecular layer. Our initial analysis included all cells that had at least $40 \%$ of the dendritic tree length in the analyzed section, and suggested that older adult-born neurons had more intersections at distal dendritic regions. However, these results were biased by the larger number of cut dendrites in the 16week-old neonatal group relative to the adult-born neuron groups. We therefore excluded cells where $<70 \%$ of the total dendritic length was present in the analyzed section, and found 10-30 neurons per group that fit this criterion. Younger cells still tended to have more complete neurons, but group differences were not statistically significant (percentage of neurons present in the analyzed section, $F_{(4,88)}=2.6, p=0.04$; post hoc comparisons: all $p>0.05$; number of cut dendrites: $F_{(4,88)}=3.1, p=0.02$; post hoc comparisons: all $p>0.05)$. The Sholl analysis revealed 


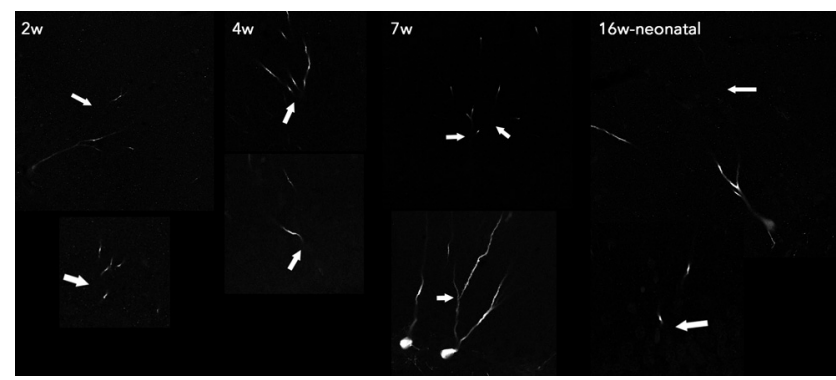

Movie 1. Dendrite trifurcation. This video shows confocal z-stack animations that focus through dendritic trees of 2-, 4-, 7-, and 16-week-old neonatal cells. Arrows indicate points where dendrites trifurcate. w, Week. [View online]

that the number of dendritic branch intersections increased at progressively greater distances from the cell soma (Fig. 2d). Neonatal-born neurons had more intersections than adult-born groups at proximal dendritic regions, reflecting their positioning in the superficial granule cell layer, closer to the inner molecular layer. Immature, 2-week-old cells had fewer dendritic intersections in proximal and distal regions, but were not different from the other groups in the intermediate dendritic tree. Proximal and distal dendritic intersections continued to increase from 4 to 7 weeks of cell age, at which point adult-born neurons were comparable to neonatal-born neurons, aside from having fewer intersections at the proximal dendritic tree.

To obtain a complementary measure of dendritic structure that is independent of dendritic length and is not influenced by tissue sectioning, we quantified the total number of dendritic branches across the full dendritic tree (Fig. 2e). Consistent with recent in vivo and in vitro results (Gonçalves et al., 2016; Beining et al., 2017; Jungenitz et al., 2018), we observed significantly greater numbers of dendritic branches in immature cells. The 2week-old cells had the most dendritic branches; there was significant pruning of branches from 2 to 4 weeks, and no changes from 4 to 7 weeks. However, the total number of dendritic branches then increased between 7 and 24 weeks, indicating a later wave of dendritic growth in adult-born neurons.

To identify where dendritic branching differed, we quantified branching according to order, where primary branches are those that emanate directly from the cell body, and the order increases by 1 with each branch point (Fig. $2 f$ ). Dendrites typically bifurcated at branch points, but trifurcation was also observed in all groups except the 24 -week-old group. Overall, $13 \%$ of cells trifurcated (2-week-old group, 16 of 77 cells; 4-week-old group, 6 of 49 cells; 7-week-old group, 7 of 64 cells; 24 -week-old group, 0 of 37 cells; 16-week-old (neonatal) group, 14 of 73 cells; Movie 1, examples). Consistent with the Sholl data, the number of lowerorder $\left(1^{\circ}-3^{\circ}\right)$ branches increased as adult-born cells aged and, by 24 weeks, was comparable to those in neonatal-born cells. Adult-born neurons are commonly recognized to have a single primary dendrite (Wang et al., 2000; Kerloch et al., 2019), which we observed in 2- to 7-week-old cells. However, by 24 weeks adultborn cells had, on average, two primary dendrites. Quaternary branches were the most common and did not differ across groups. Whereas the number of lower-order dendrites correlated with cell age, the number of higher-order dendrites tended to show the opposite pattern. The 2 -week-old cells had significantly more highorder branches $\left(5^{\circ}, 6^{\circ}\right)$ compared with all other groups. Neonatalborn neurons had the fewest $5^{\circ}$ branches.

Finally, we calculated the branching index of cells, a measure that normalizes dendritic branching to the number of primary dendrites (branch tips/number of primary dendrites; Fig. $2 g$ ).
The branching index was greater in 2-week-old cells than in all other groups. In older cells, the distribution of branching indices tended to be bimodal; cells with a single primary dendrite had a branching index that was approximately twice that of cells with two or more primary dendrites. When we excluded cells that had more than one primary dendrite, 2 -week-old cells still had a greater branching index than all older-aged adult-born cells, indicating that their greater branching index is due to more extensive distal branching and not simply because they tend to only have one primary dendrite.

Our branch order analyses raise the question of how adultborn neurons gain additional primary dendrites. A second primary dendrite could be generated de novo from the cell body or it could arise by branching off of the existing dendritic tree. It seemed unlikely that additional primary dendrites arise via sprouting because, of the 294 cells examined, only 4 cells possessed an unbranched primary dendrite and only 1 of these cells was adult born ( 24 weeks). We therefore hypothesized that new primary dendrites may emerge from the existing dendritic tree, via an "unzipping" of the primary dendrite until the first branch point meets the soma. Indeed, among cells with a single primary dendrite, we found a significant shortening between 2 and 4 weeks (Fig. 3a). There were no further changes, possibly because the cells with the shortest primary dendrites become excluded from the analysis as they mature and gain a second primary dendrite.

From 2 to 24 weeks, there was a gradual transition from cells having only a single primary dendrite to having two or more primary dendrites (Fig. $3 b$ ). Since the biggest transition occurred between 7 and 24 weeks, we focused on 7 weeks for further analyses. We reasoned that, if primary dendrites "unzip," there should be similar patterns of branching in cells with one versus two primary dendrites. Indeed, when we excluded the primary dendrite from cells with only one primary dendrite (1P), the branch order pattern became identical to cells that had two primary dendrites (2P; Fig. $3 c, d$ ). We then examined the branch index and the total length of $1^{\circ}$ branch trees (i.e., trees associated with a primary dendrite; a $1 \mathrm{P}$ cell will have one, and a $2 \mathrm{P}$ cell will have two $1^{\circ}$ branch trees). For both measures, $1^{\circ}$ branch trees of $1 \mathrm{P}$ cells were double that of $2 \mathrm{P}$ cells, consistent with a model where unzipping a longer, more complex $1^{\circ}$ branch tree results in two simpler $1^{\circ}$ branch trees (Fig. $3 e$ ). However, $1^{\circ}$ branch trees had a much greater range of total lengths and were more variable in $2 \mathrm{P}$ cells, suggesting within-cell variation in $1^{\circ}$ branch tree complexity (branch index coefficients of variation (CVs): $2 \mathrm{P}$ cells, $45 \%$; $1 \mathrm{P}$ cells, $14 \%$; length CVs: $2 \mathrm{P}$ cells, $34 \% ; 1 \mathrm{P}$ cells, $18 \%$ ). If $2 \mathrm{P}$ cells have one $1^{\circ}$ branch tree that is less developed than the other, this could be due to immaturity (supporting a sprouting model) or it could be an innate property that existed before unzipping. If innate, then differences in dendritic complexity should be apparent in the $2^{\circ}$ branch trees of $1 \mathrm{P}$ cells that have not (yet) unzipped. To test this, we compared the branching order, branch index, and total length of $1^{\circ}$ branch trees (2P cells) and $2^{\circ}$ branch trees (1P cells; Fig. $3 f-i$ ). For all measures, there was within-cell variation where a "high" branch tree had significantly greater complexity and length compared with a "low" branch tree. This pattern was observed in both $1 \mathrm{P}$ cells and $2 \mathrm{P}$ cells, supporting a model where inherent differences in dendritic subtrees exist before a primary dendrite unzips to form two primary dendrites in an adult-born neuron (Fig. 3j). Further, the average and minimum total lengths of low $1^{\circ}$ branch trees on $2 \mathrm{P}$ cells were 1012 and $499 \mu \mathrm{m}$, respectively. To sprout trees of these lengths from 4 to 7 weeks, dendrites would have to grow at rates of 48 and 

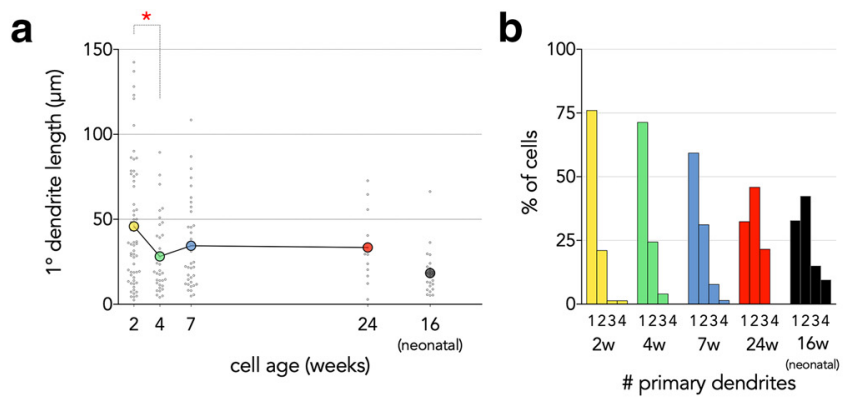

C

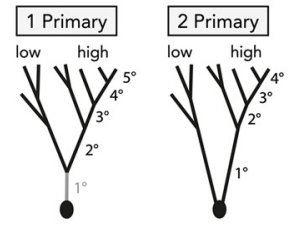

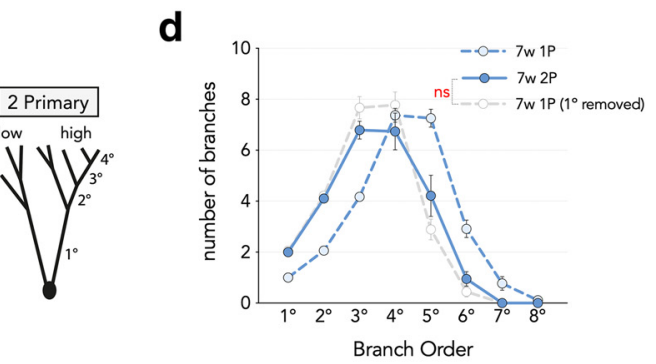

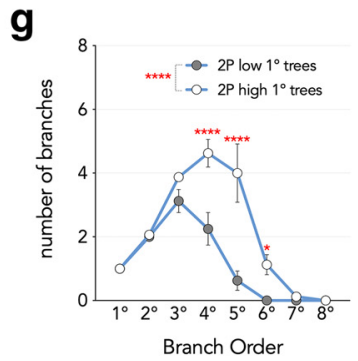

Branch Order e

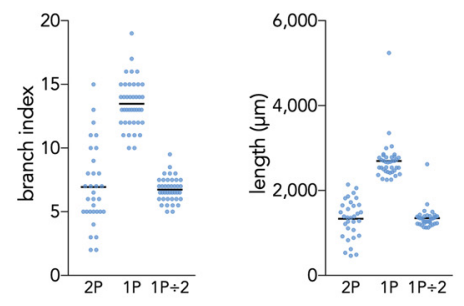

$\mathbf{f}$

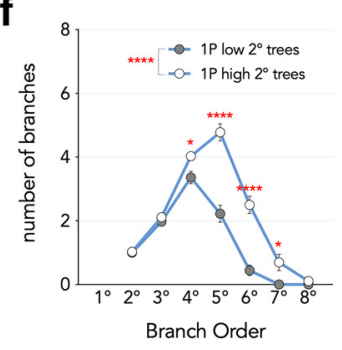

h

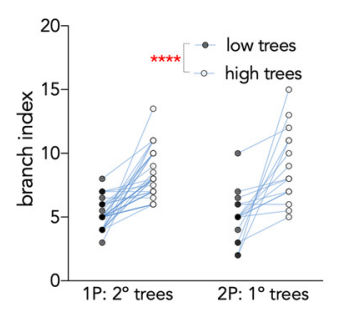

i

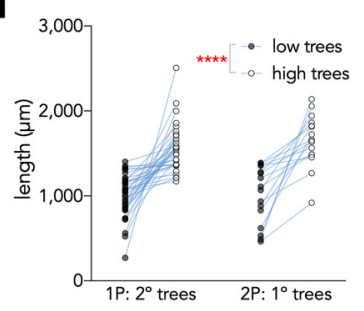

j

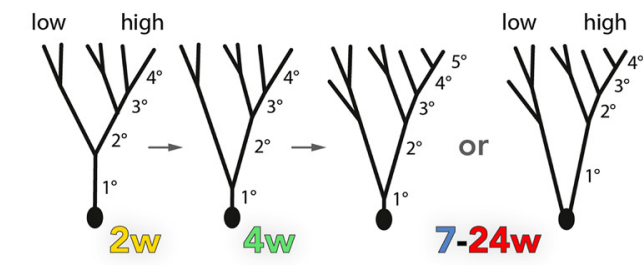

Figure 3. Unzipping model of primary dendrite formation. $\boldsymbol{a}$, The primary dendrite shortens between 2 and 4 weeks of cell age (only includes cells with a single primary dendrite; $F_{(4,167)}=$ $5.1, p=0.0007)$. $\boldsymbol{b}$, The number of primary dendrites per cell, by age. $\boldsymbol{c}$, Schematic of approach for comparing branch-tree morphology in cells with 1 primary dendrite (1P) versus 2 primary dendrites (2P). By "removing" the primary dendrite from $1 \mathrm{P}$ cells, their dendritic trees could be directly compared with $2 \mathrm{P}$ cells. Low trees had fewer branches and shorter total length than high trees (see below). $\boldsymbol{d}$, Dendritic branch orders are similar in 7-week-old $1 \mathrm{P}$ and 7-week-old $2 \mathrm{P}$ cells, once the number of primary dendrites is accounted for (7-week-old 2P vs 7-week-old $1 \mathrm{P}$ with $1^{\circ}$ dendrite removed; effect of cell type: $F_{(1,35)}=0.03, p=0.9$; cell type $\times$ branch order interaction: $F_{(6,210)}=2.2, p=0.04$; post hoc comparisons at each order, all $\left.p>0.1\right)$. $\boldsymbol{e}$, Primary dendritic trees on 7-week-old $2 \mathrm{P}$ cells displayed more variable degrees of complexity than primary dendritic trees of 7-week-old $1 \mathrm{P}$ cells, as measured by the branch index and total length. $\boldsymbol{f}$, The 7-week-old $1 \mathrm{P}$ cells had one $2^{\circ}$ dendritic tree that branched significantly less (low) than the other (high; effect of tree type: $F_{(1,35)}=53, p<0.0001$; tree type $\times$ branch order interaction: $\left.F_{(6,210)}=24, p<0.0001\right)$. $g$, The 7-week-old cells with two primary dendrites had one $1^{\circ}$ dendritic tree that branched significantly less than the other (effect of tree type: $F_{(1,15)}=$ $16, p<0.01$; tree type $\times$ branch order interaction: $\left.F_{(7,105)}=9.8, p<0.0001\right)$. $\boldsymbol{h}$, The 7-week-old cells had two main dendritic trees that differed in the amount of branching, regardless of whether the cells had 1 or 2 primary dendrites (effect of tree type: $F_{(1,50)}=67, p<0.0001$; tree type $\times$ cell type interaction: $\left.F_{(1,50)}=1.0, p=0.3\right)$. $i$, High trees had greater total dendritic length than low trees, in both cells with one and two primary dendrites (effect of tree type: $F_{(1,50)}=71, p<0.0001$; tree type $\times$ cell type interaction: $F_{(1,50)}=0.4, p=0.5$ ). $\boldsymbol{j}$, Unzipping model: the dendritic tree of adult-born neurons is inherently variable, with some "subtrees" having more branches than others. Most adult-born neurons begin with a single primary dendrite, which shortens as the first branch point moves closer to the soma. In many cells, the first branch point reaches the soma causing the transition from one to two primary dendrites, and differential complexity carries over as $2^{\circ}$-based subtrees become $1^{\circ}$-based subtrees. ${ }^{*} p<0.05$, ${ }^{* * * *} p<0.0001$. w, Week; ns, not significant.

$15 \mu \mathrm{m} / \mathrm{d}$, respectively, which is unlikely given that the average rate of dendritic growth for the entire dendritic tree over this interval was only $15 \mu \mathrm{m} / \mathrm{d}$.

\section{Spines}

To assess putative postsynaptic targets of cortical and subcortical axons, protrusion densities on DG neurons were quantified throughout the molecular layer (Fig. 4). The total number of cells examined were as follows: 85 (2 weeks), 46 (4 weeks), 66 (24 weeks), 76 [16 weeks (neonatal)]. There were few protrusions on 2-week-old cells $(0.2 / \mu \mathrm{m})$, but a dramatic $500 \%$ increase occurred between 2 and 4 weeks and a further $80 \%$ increase from 4 to 7 weeks. Total protrusion densities did not increase further between 7 and 24 weeks, but plateaued at levels that were $\sim 60 \%$ greater than neonatal-born neurons (Fig. 4b).

Protrusion densities for cells of a given age were similar whether calculated by averaging animal means or by pooling and averaging all cells ( $<4 \%$ difference). The same pattern of differences was also observed when groups were composed of animal- averaged data rather than individual-cell data $\left(\mathrm{F}_{(4,54)}=205\right.$; all comparisons, $p<0.0001$; except 4 - vs 16 -week-old (neonatal), $p=0.08$; and 7 vs 24 weeks, $p=0.4$ ).

Distinct inputs are segregated along granule neuron dendritic trees, where the lateral entorhinal cortex targets the outer molecular layer, the medial entorhinal cortex targets the middle molecular layer and subcortical and commissural fibers target the inner molecular layer (Leranth and Hajszan, 2007; Witter, 2007). We therefore examined whether the maturational profile of postsynaptic sites differs along these functionally relevant anatomical subregions and found fewer protrusions in the inner molecular layer at 4 and 7 weeks of age (Fig. 4c). This regional difference was absent by 24 weeks of age and was not present in neonatalborn neurons, suggesting delayed maturation of commissural and/or subcortical inputs onto adult-born neurons. Consistent with these data, protrusion density was generally not different across dendritic branch orders, except for 2- and 4-week-old cells, which had lower densities on primary and secondary branches compared with their higher-order branches (Fig. $4 d$ ). 
a

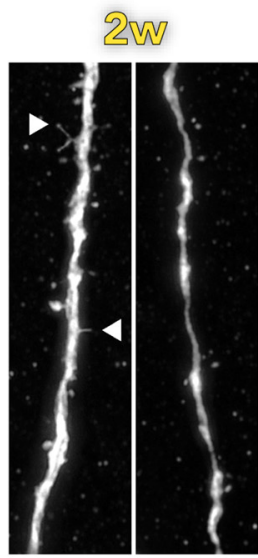

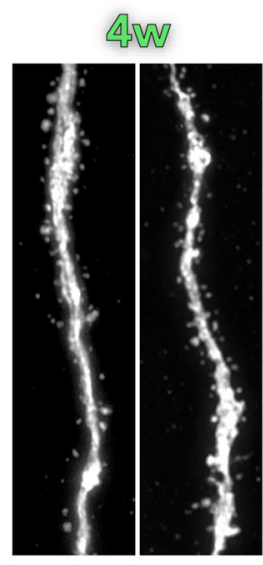
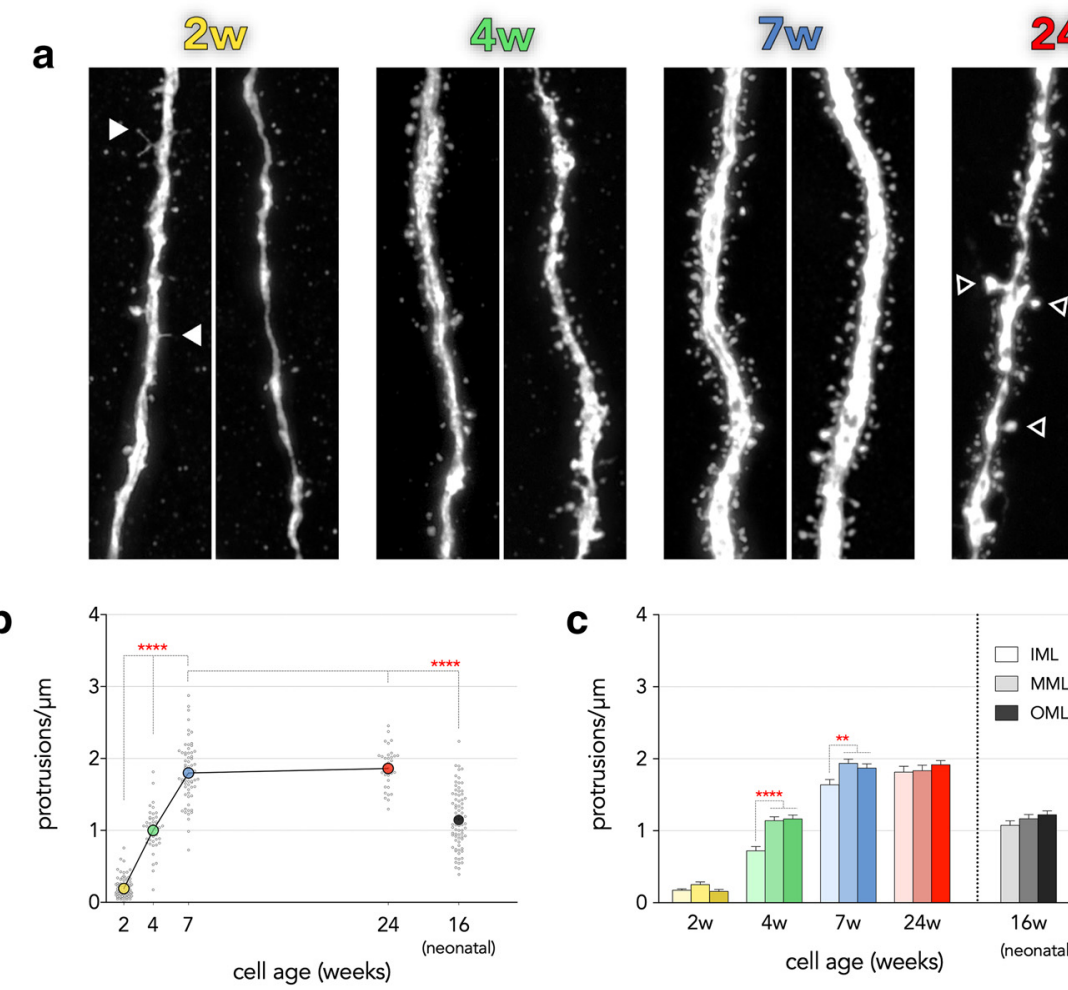

e

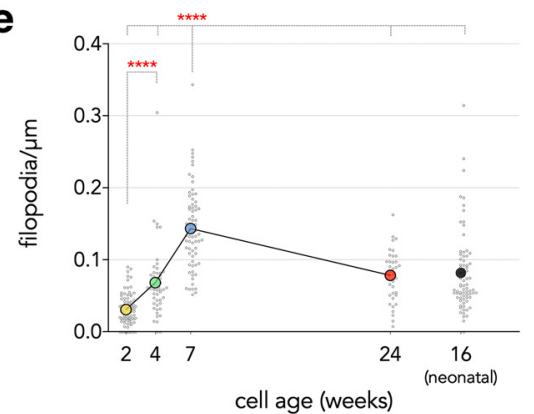

h

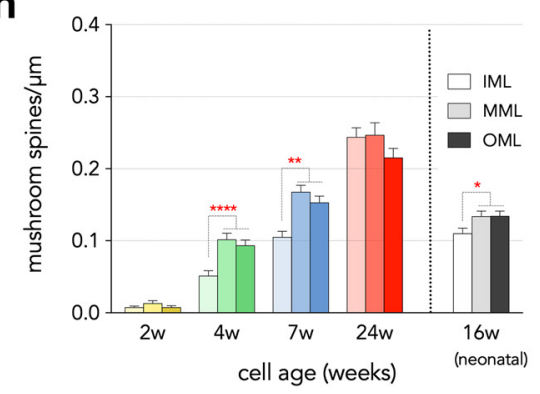

C

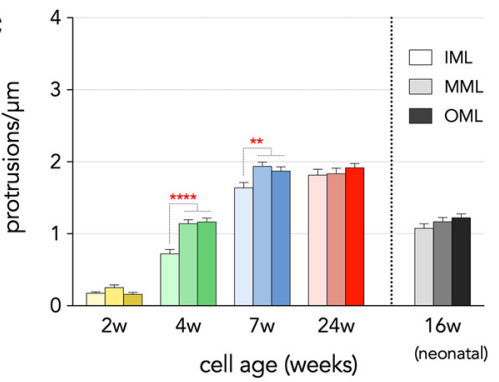

f

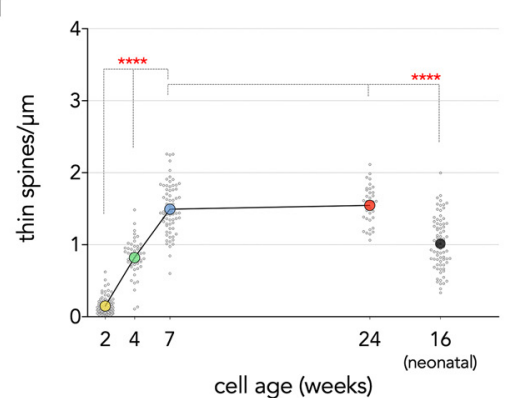

i

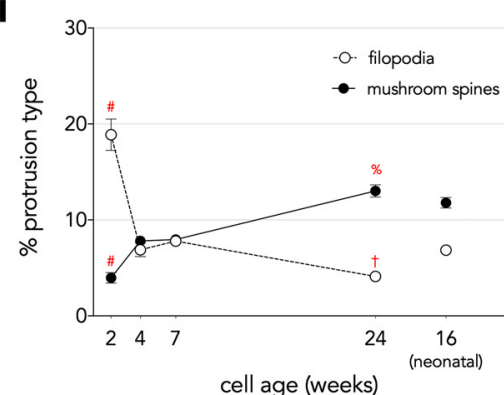

$16 w$ (neonatal)

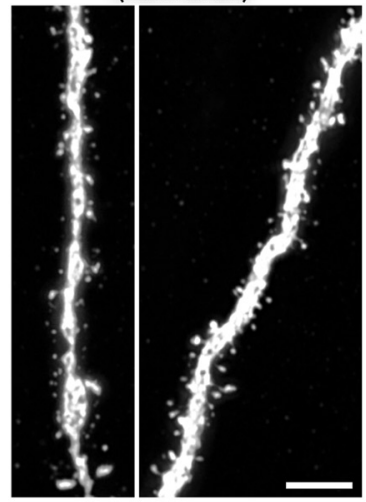

d

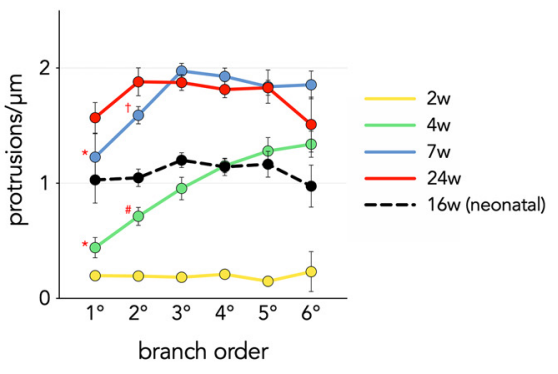

g

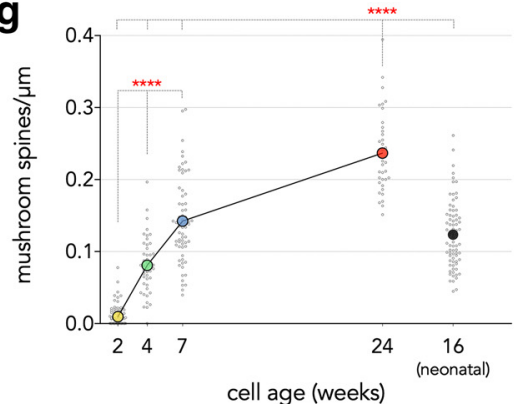

Figure 4. Spine densities in adult-born neurons reach and surpass that of neonatal-born neurons. $\boldsymbol{a}$, Confocal images of spines/protrusions. Filled arrowheads in the 2 week example indicate filopodia; open arrowheads in the 24 week example indicate mushroom spines; the segment identified by arrows at 24 weeks demonstrates a region of low spine density in the distal tip of a dendrite in the outer molecular layer. Scale bar, $10 \mu \mathrm{m} . \boldsymbol{b}$, Total protrusion densities increase with age in adult-born neurons, and plateau by 7 weeks at levels that are greater than those in neonatal-born neurons $\left(F_{(4,314)}=299, p<0.0001\right)$. c, Protrusion densities increased with cell age at a slower rate in the inner molecular layer than in the middle and outer molecular layers (cell age $\times$ layer interaction: $\left.F_{(8,883)}=3.5, p=0.0005\right)$. $\boldsymbol{d}$, In immature neurons, protrusion densities were reduced in lower-order dendrites (branch order $\times$ cell age interaction: $F_{(20,615)}=$ $2.9, p<0.0001 ; 1^{\circ}$ vs $3^{\circ}, 4^{\circ}, 5^{\circ}, 6^{\circ},{ }^{*} p<0.05 ; 2^{\circ}$ vs $4^{\circ}, 5^{\circ}, 6^{\circ}$, \#p $<0.01 ; 2^{\circ}$ vs $3^{\circ}, 4^{\circ}$. $t p<0.01$ ). e, Filopodia densities increased from 2 weeks to peak levels at 7 weeks, and declined by 24 weeks, which was not different than neonatal-born neurons $\left(F_{(4,314)}=65, p<0.0001\right)$. $f$, Thin spines made up the majority of protrusions and increased over 7 weeks to levels that were greater than neonatal-born neurons $\left(F_{(4314)}=335, p<0.0001\right)$. $g$, Mushroom spine densities increased as adult-born neurons aged and, by 24 weeks, were greater than those of all other groups $\left(F_{(4,314)}=201, p<0.0001\right)$. $\boldsymbol{h}$. Mushroom spine densities increased with adult-born neuron age at a slower rate in the inner molecular layer. Mushroom spine densities were also lower in the inner molecular layer of neonatal-born neurons (cell age $\times$ subregion interaction $\left(F_{(8,883)}=4.7, p<0.001\right)$. $\boldsymbol{i}$, The proportion of filopodial protrusions was greatest in 2-week-old cells, and the proportion of mushroom spines was greatest in 24-week-old cells (Kruskal-Wallis tests for both protrusion types, $p<0.0001$ ). Symbols and bars indicate mean values, error bars indicate the SEM. IML, Inner molecular layer; MML, middle molecular layer; OML, outer molecular layer. ${ }^{*} p<0.05$, ${ }^{* *} p<0.01,{ }^{* * *} p<0.001$, ${ }^{* * *} p<0.0001$, \#p $<0.001$ versus the same protrusion type at all other ages; \%p $<0.0001$ versus the same protrusion type at 4 and 7 weeks; $t p<0.05$ versus the same protrusion type at 4,7 , and 16 weeks (neonatal). w, Week. 
a
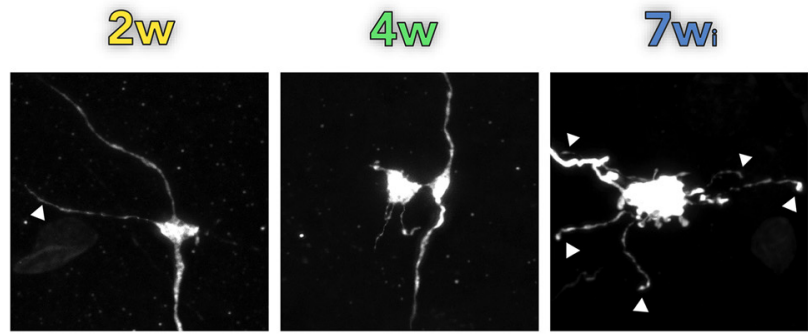

b

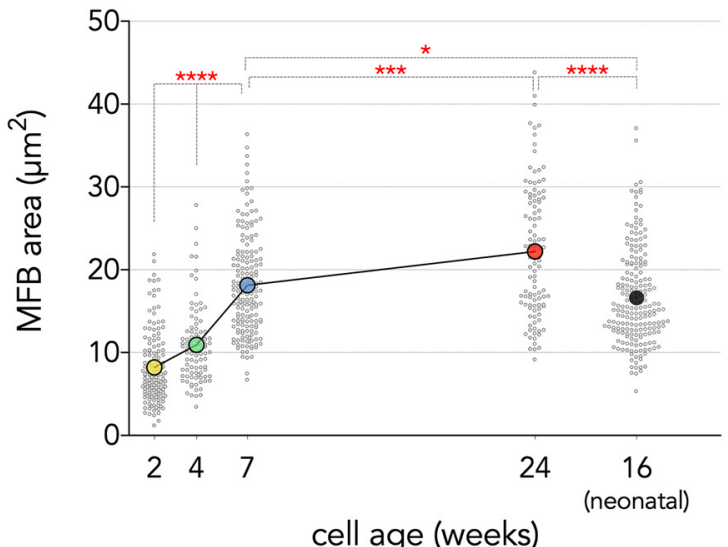

d

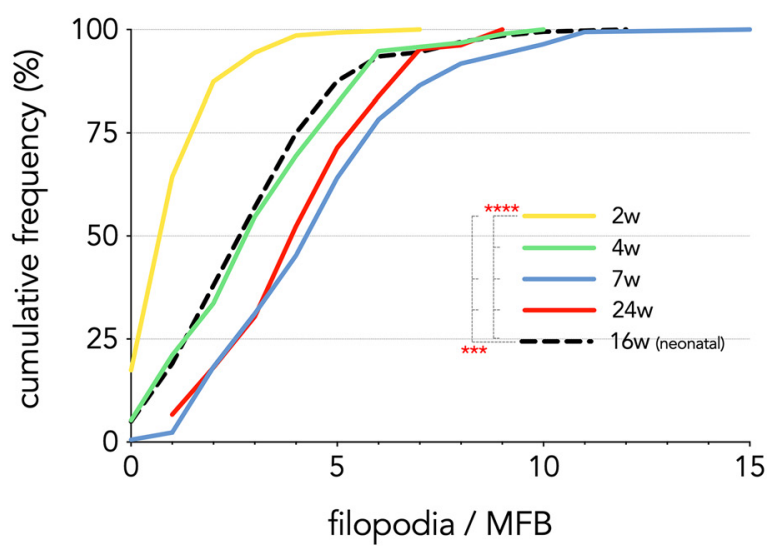

f

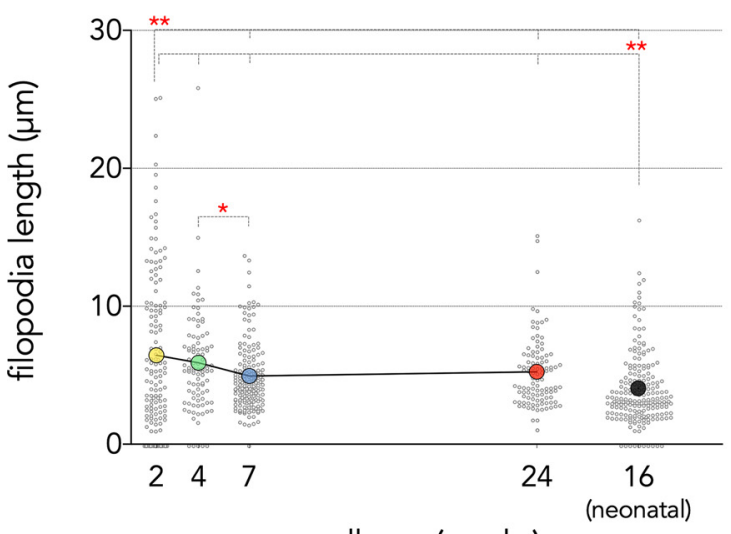

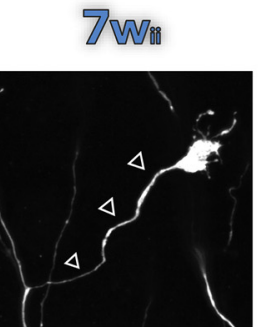
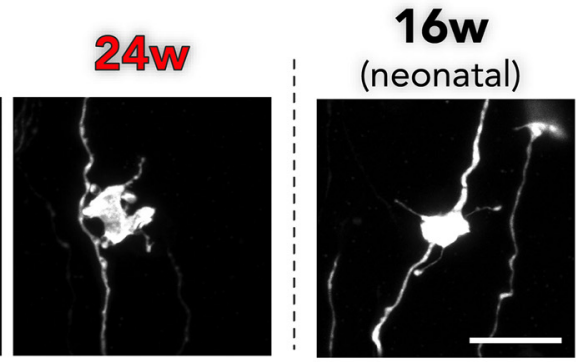

C

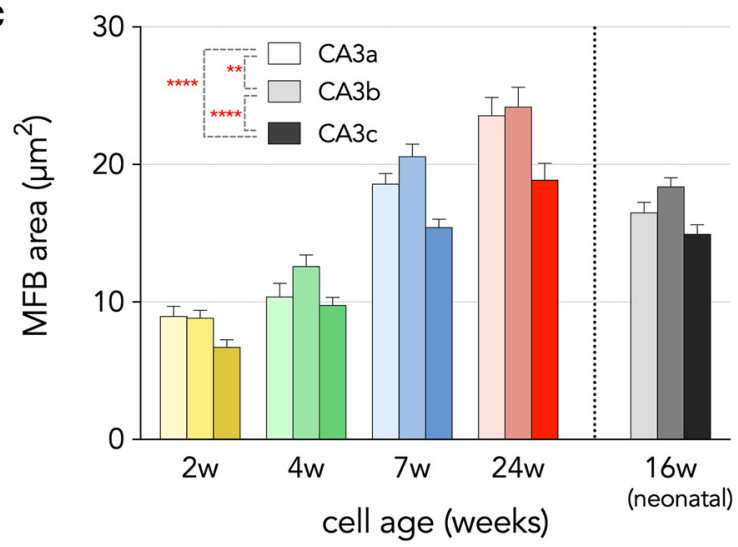

e

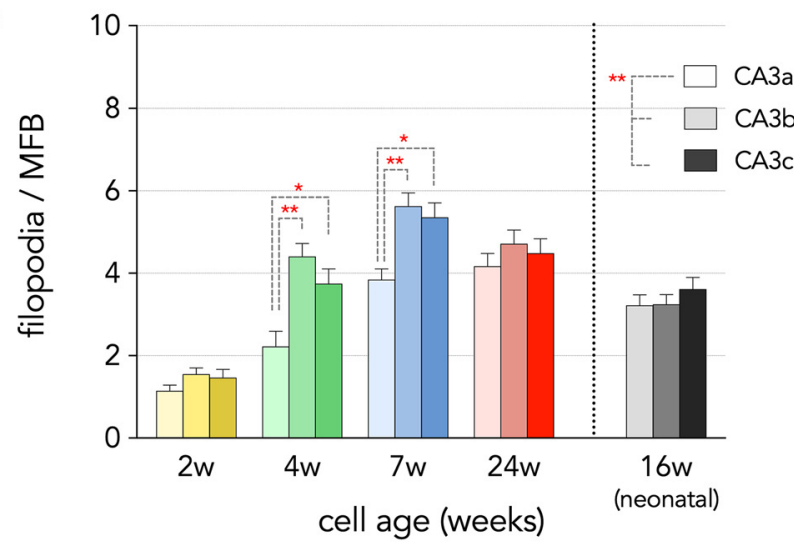

g

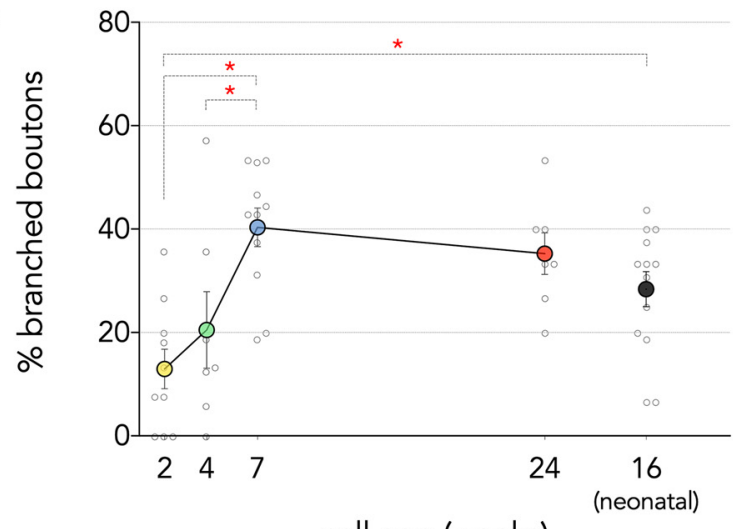

cell age (weeks)

Figure 5. Efferent synaptic terminals of neonatally and adult-born neurons. $\boldsymbol{a}$, Confocal images of retrovirally labeled MFBs and filopodial terminals. Filled arrowheads in 2 week and $7 w_{i}$ images indicate filopodial extensions. Open arrowheads in $7 \mathrm{w}_{\mathrm{ii}}$ indicate a branched MFB. Scale bars: for all images except for $7 \mathrm{w}_{\mathrm{ii}}, 10 \mu \mathrm{m} ; 7 \mathrm{w}_{\mathrm{ii}}, 11.7 \mu \mathrm{m}$. $\boldsymbol{b}, \mathrm{MFBs}$ increased in size with cell age $\left(F_{(4,708)}=160, p<0.0001\right)$. c, MFBs increased in size from CA3c $<$ CA3a $<$ CA3b (effect of subregion: $F_{(2,698)}=26, p<0.0001$; cell group $\times$ subregion interaction: $F_{(8,698)}=1.2$, $p=0.3$ ). $\boldsymbol{d}$, The number of filopodia per MFB increased from 2 to 7 weeks and remained greater than neonatal-born neurons at 24 weeks (Kruskal-Wallis test, $p<0.0001) . \boldsymbol{e}$, The number of filopodia per MFB was lowest in CA3a, specifically in 4- and 7-week-old cells (effect of subregion: $F_{(2,698)}=15, p<0.0001$; cell group $\times$ subregion interaction: $F_{(8,698)}=2.8, p=0.005$ ). $\boldsymbol{f}$, Filopodia length was greatest at 2 weeks and decreased with cell age but remained longer than neonatal-born neurons $\left(F_{(4,667)}=18, p<0.0001\right)$. $\boldsymbol{g}$, The proportion of branched MFBs 
Spines can be categorized into functionally relevant subclasses based on morphology, where thin filopodial protrusions tend to be transient, plastic potential synaptic partners and large mushroom spines are structurally stable, synaptically stronger, and believed to be sites of long-term information storage (Holtmaat and Svoboda, 2009; Berry and Nedivi, 2017). Consistent with a developmental role, filopodia density peaked at 7 weeks (Fig. 4e). The density of thin spines followed the same pattern as the protrusion densities, and accounted for most of the protrusions (Fig. $4 f)$. We additionally quantified large mushroom spines in DG neurons of different ages (Fig. $4 g$ ). Whereas mushroom spines were virtually absent from young 2 -week-old cells, they steadily increased with age. At 24 weeks, the densities of mushroom spines were greater than all other groups, and they were nearly twice as common as in neonatal-born neurons. The regional distribution of mushroom spines resembled the overall spine density pattern, where fewer mushroom spines were found in the inner molecular layer on 4- and 7-week-old neurons (Fig. 4h). Here, however, there were also fewer mushroom spines observed on neonatal-born neurons in the inner molecular layer. Examining the changes in proportion of spine type revealed a clear maturational profile, where filopodia made up the largest proportion of protrusions at 2 weeks and declined with age; mushroom spines followed the opposite pattern (Fig. 4i).

\section{Presynaptic terminals}

Dentate granule neuron MFBs are large excitatory presynaptic structures, composed of multiple active zones that target CA3 pyramidal neurons and mossy cells (Chicurel and Harris, 1992; Rollenhagen et al., 2007). Associated with each MFB are smaller filopodial extensions that form synapses with inhibitory neurons (Acsády et al., 1998). To gain insights into the role that cell age may play in efferent connectivity, we first quantified the maximal $2 \mathrm{D}$ area of MFBs as an anatomical proxy for synaptic strength. The total number of MFBs examined was as follows: 143 (2 weeks), 95 (4 weeks), 170 (7 weeks), 105 (24 weeks), 200 [16 weeks (neonatal)]. Among adult-born neurons, MFBs doubled in size between 2 and 7 weeks, with most growth occurring between 4 and 7 weeks. However, they grew an additional 20\% between 7 and 24 weeks. At 24 weeks, adult-born MFBs were 34\% larger than 16 week neonatal-born neurons (Fig. 5b). Across all cell populations, MFBs were smaller in CA3c than in CA3a/b (Fig. $5 c$ ).

MFB sizes that were calculated from animal averages differed by $\leq 5 \%$ from means that were calculated by pooling all cells within a given age group. The same pattern of group differences was also observed when animal-averaged data were analyzed rather than individual cell data $\left[F_{(4,43)}=45\right.$, all groups significantly different from one another $(p<0.05)$ except 7 vs 16 week-old (neonatal) cells $(p=0.13)]$.

We next examined the filopodial processes that protrude from MFBs and contact GABAergic interneurons. There was an age-related increase in filopodia/MFB from 1.4 filopodia/MFBs at 2 weeks to $4-5$ filopodia/MFBs at 7 and 24 weeks, which was significantly greater than that of neonatal-born cells (3.4; Fig. $5 d)$. There were also fewer filopodia/MFBs in CA3a, an effect that was driven by 4 - and 7-week-old cells (Fig. 5e). While young 2-week-old cells had few filopodia/MFBs, their filopodia were

$\leftarrow$

increased with cell age and did not differ significantly between older adult-born neurons and neonatal-born neurons $\left(F_{(5,47)}=6, p<0.001\right)$. ${ }^{*} p<0.05$, ${ }^{* *} p<0.01$, ${ }^{* * *} p<0.001$, ${ }^{* * * *} p<0.0001$. w, Week. significantly longer than those of older adult-born and neonatalborn neurons (Fig. 5f). Filopodial length declined from a mean of $7 \mu \mathrm{m}$ at 2 weeks to $\sim 5 \mu \mathrm{m}$ at 7 weeks, which was not different from 24-week-old adult-born neurons. Filopodia length of neonatal-born neurons was shorter than all adult-born populations. Filopodia were longer in CA3c than in CA3a, an effect that was not specific to any subpopulation of cells (effect of subregion: $F_{(2,657)}=4.8, p=0.008$; subregion $\times$ cell age interaction: $\left.F_{(8,657)}=1.4, p=0.2\right)$.

In addition to age-related changes in MFB size, there were also differences in the positioning of MFBs relative to the axon (Fig. 5g). Young adult-born cells, 2-4 weeks old, tended to have en passant MFBs that were located directly on the axon. In contrast, $30-40 \%$ of MFBs on older adult-born cells and neonatalborn cells were connected to the axon by a branch. Branch lengths averaged $8 \mu \mathrm{m}$ across all cells examined: $75 \%$ of branches were $<10 \mu \mathrm{m}$ in length; the longest branch was $52 \mu \mathrm{m}$. There were no differences in branch length across cell groups or CA3 subregions (group effect: $F_{(4,207)}=1.8, p=0.12$; CA3 subregion effect: $F_{(2,207)}=0.1, p=0.9$; interaction, $\left.F_{(8,207)}=0.9, p=0.5\right)$.

\section{Soma and nuclear size}

Our analyses indicate an extended developmental trajectory for adult-born neurons, where several morphological features ultimately surpass neonatal-born neurons in size. We tested the generality of our findings by measuring the size of the cell soma and nucleus, both of which vary as adult-born neurons mature (Kirn et al., 1991; van Praag et al., 2002; Amrein and Slomianka, 2010; Radic et al., 2015; Moreno-Jiménez et al., 2019; Fig. 6). Consistent with early growth, the cell soma increased in size from 2 to 7 weeks and was stable thereafter, similar to neonatalborn neurons. In contrast, the nuclear size was generally smaller in adult-born cells than in neonatal-born cells, except at 7 weeks when adult-born cells had larger nuclei that matched 16-weekold neonatal cells in size.

\section{Morphological differences are not due to animal age}

The morphology of developmentally born granule cells differs depending on whether cells were born embryonically or neonatally (Kerloch et al., 2019), and differences in experience-dependent gene expression have been observed in cells born at different stages of adulthood (Tronel et al., 2015; Ohline et al., 2018). Thus, it is possible that the observed morphological differences are due to the age of the animal at the time of cell birth, and not the age of the cells. To test this, we injected groups of rats with retrovirus at 8 or 14 weeks of age (since this bookends the full range of ages used for our analyses of adult-born cells) and examined cells 7 weeks later (Fig. 7). We observed no differences between cells born at 8 and 14 weeks for any of our key measures (dendritic length and branching, spine densities, MFB morphology). We did find that branched MFBs had longer branches in cells born at 14 weeks than in those born at 8 weeks, suggesting that terminals from later-born neurons may search a greater space to find their postsynaptic targets (Mann-Whitney $U$ test $=298$, $p=0.03)$. These data collectively indicate that morphological differences between our adult-born cell populations reflect differences in cell age rather than animal age.

\section{Modeling the cumulative effects of neuron addition and extended maturation}

Given the dramatic decline in neurogenesis with age, it has remained unclear whether new neurons contribute to the function of the aging brain. Our results suggest that extended growth 

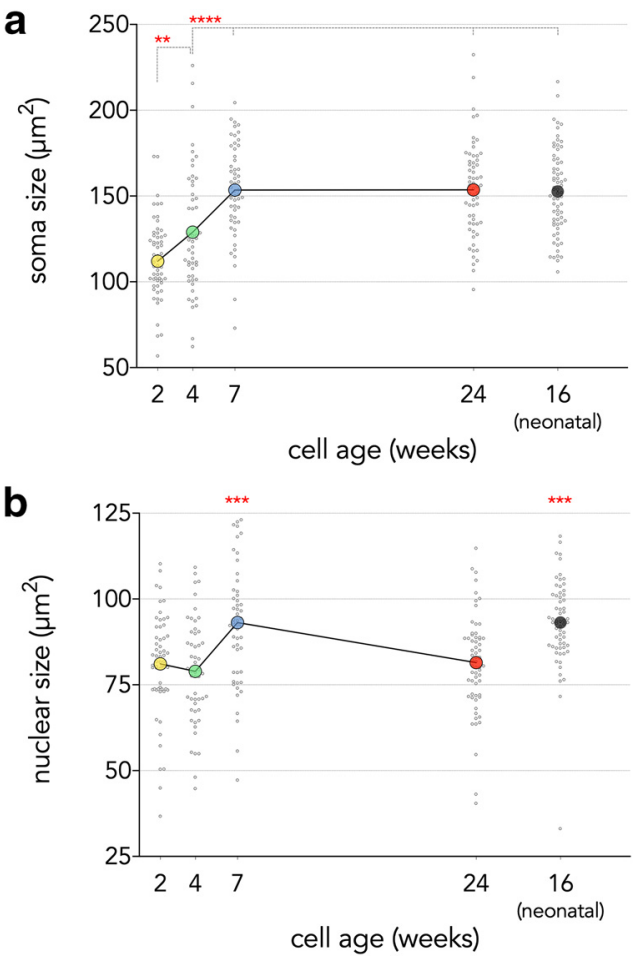

Figure 6. Soma and nuclear morphology. $\boldsymbol{a}$, The cell soma increased in size as adult-born cells aged, plateauing and matching neonatal-born neurons by 7 weeks $\left(F_{(4,289)}=27\right.$, $p<0.0001$; ${ }^{* *} p<0.01$, $\left.{ }^{* * *} p<0.0001\right)$. $\boldsymbol{b}$, The nuclear size of adult-born neurons was generally consistent across cell ages, except at 7 weeks when nuclear sizes were larger and equivalent to neonatal-born neurons $\left(F_{(4,291)}=12.5, p<0.0001\right)$. ${ }^{* *} p<0.001$ vs 2,4 , and 24 weeks.
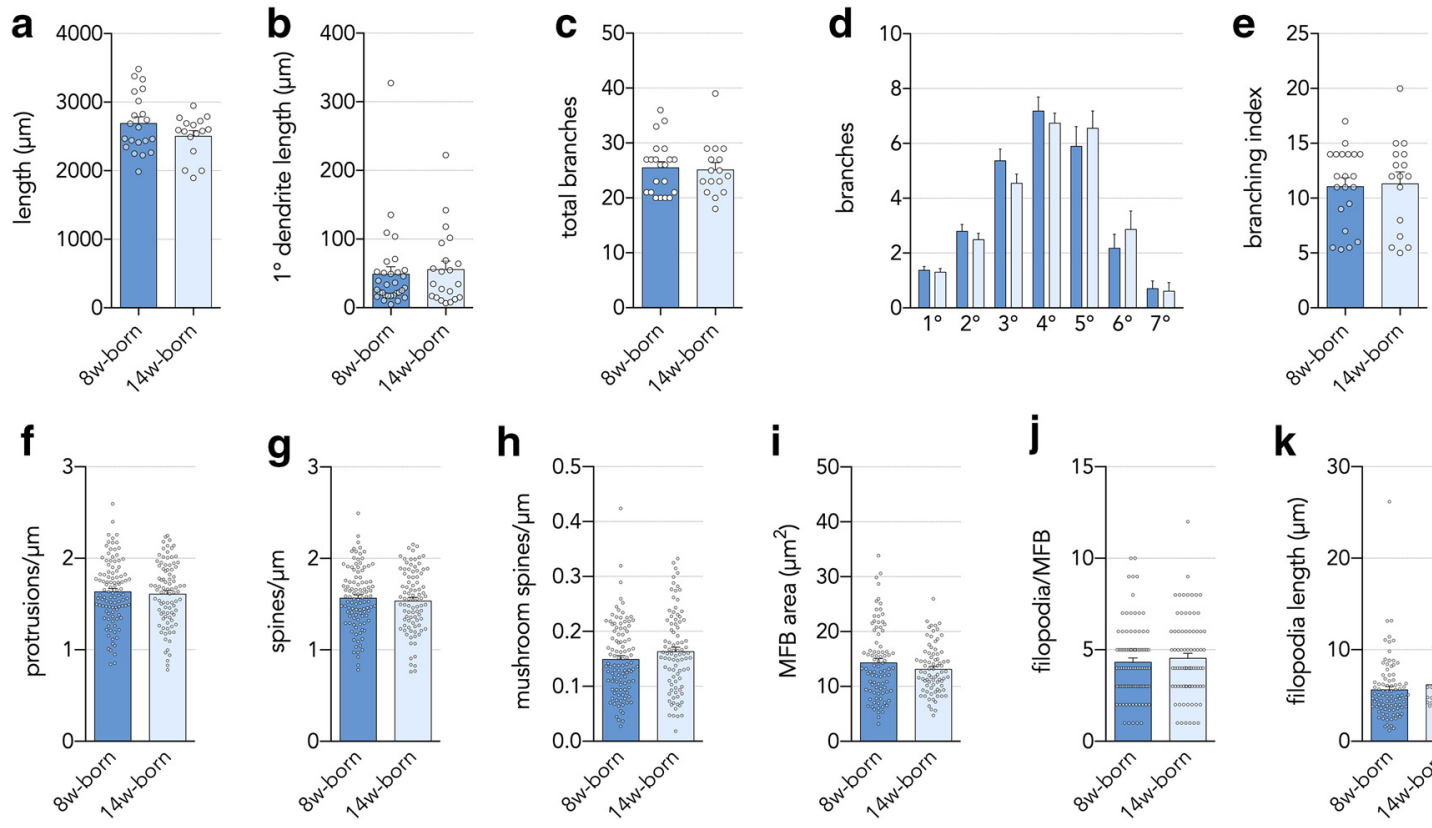

may contribute to the plasticity of the aging brain. Whereas our analyses were limited to individual cells born at a snapshot in time, an accurate representation of plasticity must account for the extended growth of all cells born throughout adult life. To estimate this, we created a model that combined and integrated rates of cell addition, dendritic growth, and spine growth from 8 weeks to 2 years of age in the rat (see Materials and Methods; Fig. $8 a-d$, functions). Consistent with previous estimates based on different datasets (Snyder and Cameron, 2012) and evidence from Glast CreERT2 mice (DeCarolis et al., 2013), our model predicts that $\sim 50 \%$ of total DG neurons are added in adulthood (Fig. 8e). A similar proportion of dendritic material in the DG can also be attributed to adult-born neurons $(\sim 4 \mathrm{~km}$ in absolute terms). Given that adult-born neurons achieve greater spine densities than neonatal-born neurons, we estimate that adult neurogenesis ultimately contributes the majority of spines in the DG (Fig. $8 g, h$ ). Notably, while neurogenesis in our model ended by 1.5 years, adult-born neurons continued to add to the total dendrite length and the total number of spines in the DG even after this point; this was particularly salient for mushroom spines. Between 1 and 2 years, we estimate that adult neurogenesis adds only $2.5 \%$ of total cells, consistent with previous quantitative estimates of neurogenesis rates later in life (Lazic, 2012), but during this time it contributes $7 \%$ of total dendritic length, $10 \%$ of total spines, and $24 \%$ of mature mushroom spines in the DG.

\section{Discussion}

Here we report that functionally relevant morphological features of adult-born neurons develop over a surprisingly long time frame. From 2 to 7 weeks, neurons displayed classic patterns of morphological maturation. However, properties of 7-week-old cells suggest a later wave of development: dendrites were thickest, nuclei were largest, and dendritic filopodia were present in the greatest numbers. By examining cells at 24 weeks, which is

Figure 7. Equivalent morphology of neurons born at different stages of young adulthood. $\boldsymbol{a}-\boldsymbol{k}$, Morphology did not differ between 7-week-old neurons that were born in 8- versus 14-week-old rats. $\boldsymbol{a}$, Total dendritic length $\left(T_{35}=1.5, p=0.15\right)$. $\boldsymbol{b}$, Primary dendrite length $\left(T_{28}=0.5, p=0.63\right)$. $\boldsymbol{c}$, Total number of dendritic branches $\left(T_{21}=0.9, p=0.4\right)$. $\boldsymbol{d}$, Branch order distribution (effect of branch order: $F_{(6,126)}=35, p<0.0001$; effect of birthdate: $F_{(1,21)}=0.8, p=0.4$; interaction: $\left.F_{(6,126)}=0.5, p=0.8\right)$. $\boldsymbol{e}$, Branching index (T. $\left.\mathrm{T}_{21}=0.3, p=0.8\right)$. $\boldsymbol{f}$, Dendritic protrusions $\left(\mathrm{T}_{193}=0.5, p=0.6\right)$. $\boldsymbol{g}$, Spines $\left(\mathrm{T}_{193}=0.7, p=0.5\right)$. $\boldsymbol{h}$, Mushroom spines $\left(\mathrm{T}_{193}=1.4, p=0.2\right)$. $\boldsymbol{i}$, MFB area $\left(\mathrm{T}_{167}=0.6, p=0.6\right)$. $\boldsymbol{j}$, Number of MFB filopodia (Mann-Whitney $U$ test $=3311, p=0.5)$. $\boldsymbol{k}$, Filopodia length $\left(T_{166}=1.2, p=0.2\right)$. w, Week. 

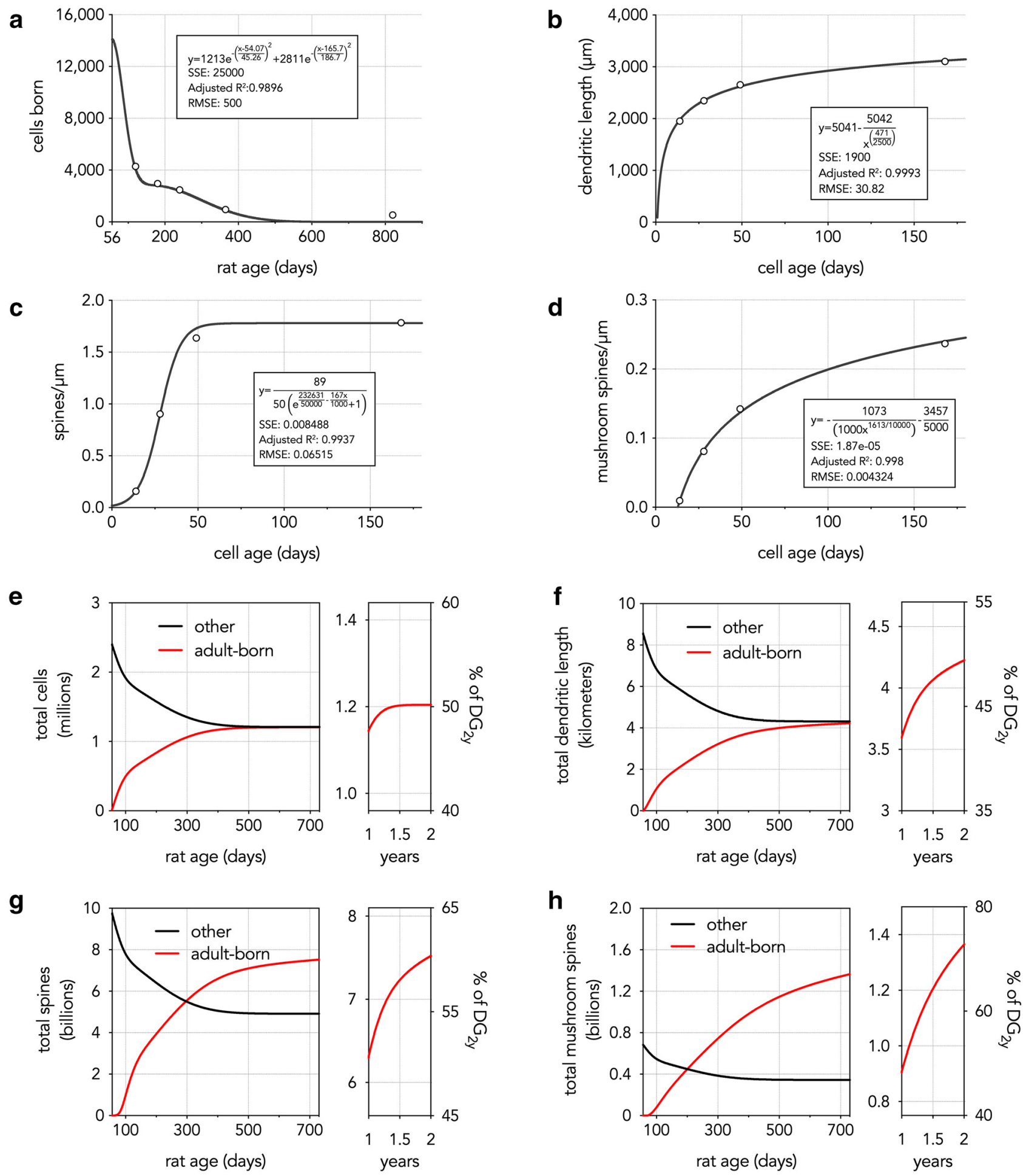

Figure 8. Modeling cumulative effects of adult neurogenesis. $\boldsymbol{a}-\boldsymbol{d}$, Functions used to model neuron addition in adulthood $(\boldsymbol{a})$, dendritic growth of adult-born neurons $(\boldsymbol{b})$, spine growth on adult-born neurons $(\boldsymbol{c})$, and mushroom spine growth on adult-born neurons $(\boldsymbol{d})$. $\boldsymbol{e}-\boldsymbol{h}$, Modeling neurogenic plasticity throughout life. Square left panels show neurogenesis effects across the full period of adulthood of a rat (8 weeks to 2 years). Narrow right panels focus on cumulative effects during the second half of life, when neurogenesis has declined but growth continues; right $y$-axis shows the percentage of the contribution by neurogenesis, relative to the total granule cell population at 2 years of life. Other/adult-born $=$ cells born before/after 8 weeks of age. $\boldsymbol{e}$, Adult-born neurons accumulate throughout the first 1.5 years of life and ultimately account for approximately half the total granule cell population (numbers are bilateral). $\boldsymbol{f}$, Total dendritic length contributed by adult neurogenesis increases throughout life, although neurogenesis ends at 1.5 years in this model. $\boldsymbol{g}, \boldsymbol{h}$, Because of the prolonged growth of dendrites and spines, the total number of spines (thin + mushroom spines; $\boldsymbol{g}$ ) and mushroom spines $(\boldsymbol{h})$ added to the dentate gyrus increases through old age. w, Week.

substantially older than in most previous studies, we found that dendrites, spines, and presynaptic terminals continued to grow and even surpass those of neonatal-born neurons. Our results are not confounded by ontogeny since neurons of the same age, born in 8- and 14-week-old rats, had equivalent morphology. Differences between 24-week-old adult-born neurons and 16week-old neonatal-born neurons are not simply due to differences in cell age (where 24-week-old adult-born neurons had more 
time to grow) because adult-born cells already had greater spine densities, larger MFBs, and more MFB filopodia by 7 weeks. In fact, developmentally born cells mature faster than adult-born neurons (Overstreet-Wadiche et al., 2006; Zhao et al., 2006; Cahill et al., 2017) and do not undergo additional dendritic growth beyond $\sim 5-6$ weeks of cell age (Kerloch et al., 2019). The 16-week-old neonatal neurons therefore reflect a relevant control population of mature neurons, though it will be important for future studies to characterize the maturational trajectory of dendrites, spines, and terminals on developmentally born neurons. While physiological experiments are needed to determine functional significance, our results indicate that adult-born neurons are plastic well beyond the traditional critical window and may make unique contributions to hippocampal functioning for the life span of the cell.

\section{Extended growth of adult-born neuron dendrites}

Immature neurons displayed a transient overproduction of distal, high-order branches, as has been previously described in vivo (Gonçalves et al., 2016) and in vitro (Beining et al., 2017). While branches were pruned between 2 and 4 weeks, total dendritic length grew significantly during this interval and dendrites continued to grow until 24 weeks. Why has the continued growth of adult-born neuronal dendrites (beyond $\sim 2$ months) not been reported previously? The most likely explanation is that most studies have not investigated older cohorts of cells (Shapiro et al., 2007; Wang et al., 2008; Leslie et al., 2011; Piatti et al., 2011; Dieni et al., 2013). While some studies have analyzed cells as old as 8-11 weeks, small sample sizes or cut dendrites may have masked growth (Sun et al., 2013; Gonçalves et al., 2016; Beining et al., 2017; Trinchero et al., 2017; Bolós et al., 2019). Quantifying growth over an extended interval of 17 weeks may also have facilitated the detection of cumulative growth that is not readily apparent over shorter intervals. Whether growth is linear between 7 and 24 weeks, and whether adult-born cells continue to grow beyond 24 weeks, remain open questions.

Whereas prolonged dendritic growth suggests a long-term plasticity function for adult-born neurons, their branching pattern matures to become broadly similar to neonatal-born neurons. Typically, adult-born neurons are considered to have only a single primary dendrite (Wang et al., 2000; Kerloch et al., 2019). However, forced swimming, inflammation, GSK-3 overexpression, and traumatic brain injury can increase the number of primary dendrites, indicating an unusual form of dendritic plasticity (Llorens-Martín et al., 2014, 2016; Villasana et al., 2015). By examining branching patterns at early and late ages, our data suggest an unzipping model where the first branch point of the primary dendrite moves closer to the soma with age (or the soma moves toward the branch point). Subtrees with variable length and branching complexity suggest that the granule cell dendritic tree is computationally compartmentalized (Losonczy et al., 2008). Furthermore, at least some mature neonatal- and adult-born neurons have morphological features of highly active granule neurons (few primary dendrites and extensive higher-order branching; Diamantaki et al., 2016).

\section{Prolonged maturation and high density of dendritic spines}

The gradual loss of immature filopodia and the acquisition of mature mushroom spines are consistent with previous evidence that spine morphology changes with adult-born cell age (Toni et al., 2007). While the inner molecular layer is the site of the first synapses onto adult-born neurons (Chancey et al., 2014), our data suggest that synaptic maturation in this region is delayed at
7 weeks but may be accelerated by a single day of water maze training. Consistent with our data, previous reports have found that adult-born neurons gain spines beyond 1 month (van Praag et al., 2002; Zhao et al., 2006; Jessberger et al., 2007; Toni et al., 2007; Jungenitz et al., 2018; Bolós et al., 2019) and display experience-dependent changes in spines and connectivity when cells are several months old (Lemaire et al., 2012; Bergami et al., 2015). We found that adult-born neurons ultimately achieved greater spine density than neonatal-born neurons, which has likely gone unnoticed since, to our knowledge, only one other study has used retrovirus to compare spine densities of developmentally and adult-born neurons (Toni et al., 2007). While that study also reported an extended period of spine formation and maturation, spine densities on old adult-born neurons (180 d) and developmentally born (P4) neurons were similar. The reason for this discrepancy is unclear but may stem from any number of methodological differences (e.g., species, sex, running, cell birthdate). Regardless, the higher spine density of adult-born neurons is consistent with Golgi studies of mice, primates, and humans that identified a subpopulation of DG granule neurons that have approximately twice the normal density of dendritic spines (Williams and Matthysse, 1983; Seress and Frotscher, 1990; Seress, 1992).

\section{Protracted growth of large mossy fiber boutons}

Mossy fiber boutons are large multisynapse complexes that target the proximal dendrites of CA3 pyramidal neurons (Amaral and Dent, 1981; Chicurel and Harris, 1992; Rollenhagen et al., 2007) and are theorized to play a dominant role in recruiting CA3 pyramidal neurons during memory encoding (Rolls, 2010). Indeed, a single mossy fiber can trigger spiking in postsynaptic pyramidal neurons (Henze et al., 2002; Vyleta et al., 2016). Retroviral studies have found that MFB size, the number of active zones, and the number of synaptic vesicles increases as adult-born cells mature over 2-10 weeks (Faulkner et al., 2008; Toni et al., 2008; Restivo et al., 2015; Bolós et al., 2019). Given the positive relationship between MFB and EPSP size (Galimberti et al., 2006, 2010), our data suggest that adult neurogenesis contributes to the heterogeneity of synaptic strength at the DG-CA3 synapse, and may produce a population of particularly powerful synapses. Since adult-born neurons initially share CA3 spines with existing neurons before developing fully independent synapses (Toni et al., 2008), and neonatal-born neurons turn over in significant numbers (Dayer et al., 2003; Cahill et al., 2017; Ciric et al., 2019), adult-born neurons may outcompete developmentally-born neurons for CA3 circuit connectivity.

Some MFBs were not directly attached to the main axon but instead were connected via a small branch. Similar "terminal boutons" in the neocortex are more morphologically plastic than en passant boutons (De Paola et al., 2006), suggesting that branched boutons may play a unique role in hippocampal function. Branching is likely to influence the signal propagation and coding properties of axons (Ofer et al., 2017), and, since voltagegated channels are differentially distributed across axonal compartments, branches could also offer an anatomical substrate for modulating the active properties of mossy fibers (Engel and Jonas, 2005; Kole et al., 2008; Rowan et al., 2016).

Thin filopodial protrusions extend off of MFBs to excite inhibitory interneurons (Acsády et al., 1998), and adult-born neurons play an important role in recruiting inhibitory networks (Drew et al., 2015; Restivo et al., 2015). Consistent with these data, we found that the number of filopodia per MFB plateaued at 7 weeks and remained greater than developmentally born 
neurons at 24 weeks. Thus, adult-born neurons may play a longterm role in shaping inhibition in CA3, which could promote memory precision (Ruediger et al., 2011; Guo et al., 2018) by reducing overlap between ensembles of neurons that represent different experiences (Niibori et al., 2012).

\section{Significance of extended development over the life span}

Critical periods endow adult-born neurons with a unique capacity for plasticity during their immature stages. However, the focus on immature neurons has come at the expense of understanding the properties of older neurons and led to the assumption that adult-born neurons lose their functional relevance with age (Snyder, 2019). By integrating the extended growth of adult-born neurons into a model of neuronal accumulation, we present evidence that neurogenesis makes a dramatic contribution to the overall structural plasticity of the dentate gyrus. Our model predicts the addition of 1.2 billion spines $(10 \%$ of the total) between 1 and 2 years, and 300 million spines $(2.5 \%$ of the total) between 1.5 and 2 years, which is after cell proliferation has ended. Since human granule neurons grow throughout middle age to old age (Flood et al., 1985; Coleman and Flood, 1987), and neonatal-born neurons in mice do not grow over similar intervals (Kerloch et al., 2019), adult-born neurons may offer a unique reserve of plasticity in aging (Kempermann, 2008), when the medial-temporal lobe becomes vulnerable to pathology (Leal and Yassa, 2015). Moreover, cellular maturation is slower in older (Trinchero et al., 2017) and longer lived animals (Kohler et al., 2011), which may further prolong neurogenesis-associated plasticity in human aging. It will be important for future work to further characterize this long-term plasticity in cells from female subjects and in other DG subregions (e.g., infrapyramidal blade, ventral DG).

Plasticity aside, our data are consistent with emerging evidence that adult-born granule neurons are functionally distinct from neurons born at other stages of life, even after they have "matured" (Snyder, 2019). The significantly greater spine density suggests that older adult-born neurons may be inherently more likely to associate, and be recruited by, cortical inputs. The presence of larger boutons suggests that adult-born neurons may be more capable of depolarizing postsynaptic pyramidal neurons, and the presence of more filopodia suggests that they may be more effective at refining CA3 representations through feedforward inhibition. Given cellular heterogeneity in disease vulnerability, protracted neurogenesis may also result in subpopulations of cells that are differentially susceptible to pathology.

\section{References}

Acsády L, Kamondi A, Sík A, Freund T, Buzsáki G (1998) GABAergic cells are the major postsynaptic targets of mossy fibers in the rat hippocampus. J Neurosci 18:3386-3403.

Aimone JB, Wiles J, Gage FH (2009) Computational influence of adult neurogenesis on memory encoding. Neuron 61:187-202.

Altman J, Das GD (1965) Autoradiographic and histological evidence of postnatal hippocampal neurogenesis in rats. J Comp Neurol 124:319335.

Alvarez DD, Giacomini D, Yang SM, Trinchero MF, Temprana SG, Büttner KA, Beltramone N, Schinder AF (2016) A disynaptic feedback network activated by experience promotes the integration of new granule cells. Science (New York, NY) 354:459-465.

Amaral DG, Dent JA (1981) Development of the mossy fibers of the dentate gyrus: I. A light and electron microscopic study of the mossy fibers and their expansions. J Comp Neurol 195:51-86.
Ambrogini P, Cuppini R, Lattanzi D, Ciuffoli S, Frontini A, Fanelli M (2010) Synaptogenesis in adult-generated hippocampal granule cells is affected by behavioral experiences. Hippocampus 20:799-810.

Amrein I, Slomianka L (2010) A morphologically distinct granule cell type in the dentate gyrus of the red fox correlates with adult hippocampal neurogenesis. Brain research 1328:12-24.

Anderson ML, Sisti HM, II DMC, Shors TJ (2010) Associative learning increases adult neurogenesis during a critical period. European Journal of Neuroscience 33:175-181.

Beining $M$, Jungenitz $\mathrm{T}$, Radic $\mathrm{T}$, Deller $\mathrm{T}$, Cuntz $\mathrm{H}$, Jedlicka $\mathrm{P}$, Schwarzacher SW (2017) Adult-born dentate granule cells show a critical period of dendritic reorganization and are distinct from developmentally born cells. Brain Struct Funct 222:1427-1446.

Bergami M, Masserdotti G, Temprana SG, Motori E, Eriksson TM, Göbel J, Yang SM, Conzelmann K-K, Schinder AF, Götz M, Berninger B (2015) A critical period for experience-dependent remodeling of adult-born neuron connectivity. Neuron 85:710-717.

Berry KP, Nedivi E (2017) Spine dynamics: are they all the same? Neuron 96:43-55.

Bird AD, Cuntz H (2016) Optimal current transfer in dendrites. PLoS Comput Biol 12:e1004897.

Bolós M, Terreros-Roncal J, Perea JR, Pallas-Bazarra N, Ávila J, LlorensMartín M (2019) Maturation dynamics of the axon initial segment (AIS) of newborn dentate granule cells in young adult C57BL/6J mice. J Neurosci 39:1605-1620.

Cahill SP, Yu RQ, Green D, Todorova EV, Snyder JS (2017) Early survival and delayed death of developmentally-born dentate gyrus neurons. Hippocampus 27:1155-1167.

Cameron HA, Woolley CS, McEwen BS, Gould E (1993) Differentiation of newly born neurons and glia in the dentate gyrus of the adult rat. Neuroscience 56:337-344.

Chancey JH, Adlaf EW, Sapp MC, Pugh PC, Wadiche JI, OverstreetWadiche LS (2013) GABA depolarization is required for experience-dependent synapse unsilencing in adult-born neurons. J Neurosci 33:66146622.

Chancey JH, Poulsen DJ, Wadiche JI, Overstreet-Wadiche L (2014) Hilar mossy cells provide the first glutamatergic synapses to adult-born dentate granule cells. J Neurosci 34:2349-2354.

Charvet CJ, Finlay BL (2018) Comparing adult hippocampal neurogenesis across species: translating time to predict the tempo in humans. Front Neurosci 12:706.

Chicurel ME, Harris KM (1992) Three-dimensional analysis of the structure and composition of CA3 branched dendritic spines and their synaptic relationships with mossy fiber boutons in the rat hippocampus. J Comp Neurol 325:169-182.

Ciric T, Cahill SP, Snyder JS (2019) Dentate gyrus neurons that are born at the peak of development, but not before or after, die in adulthood. Brain Behav 9:e01435.

Claiborne BJ, Amaral DG, Cowan WM (1986) A light and electron microscopic analysis of the mossy fibers of the rat dentate gyrus. J Comp Neurol 246:435-458.

Claiborne BJ, Amaral DG, Cowan WM (1990) Quantitative, three-dimensional analysis of granule cell dendrites in the rat dentate gyrus. J Comp Neurol 302:206-219.

Coleman PD, Flood DG (1987) Neuron numbers and dendritic extent in normal aging and Alzheimer's disease. Neurobiol Aging 8:521-545.

Dayer AG, Ford AA, Cleaver KM, Yassaee M, Cameron HA (2003) Shortterm and long-term survival of new neurons in the rat dentate gyrus. J Comp Neurol 460:563-572.

De Paola V, Holtmaat A, Knott G, Song S, Wilbrecht L, Caroni P, Svoboda K (2006) Cell type-specific structural plasticity of axonal branches and boutons in the adult neocortex. Neuron 49:861-875.

DeCarolis NA, Mechanic M, Petrik D, Carlton A, Ables JL, Malhotra S, Bachoo R, Götz M, Lagace DC, Eisch AJ (2013) In vivo contribution of nestin- and GLAST-lineage cells to adult hippocampal neurogenesis. Hippocampus 23:708-719.

Diamantaki M, Frey M, Berens P, Preston-Ferrer P, Burgalossi A (2016) Sparse activity of identified dentate granule cells during spatial exploration. Elife 5:e20252.

Dieni CV, Nietz AK, Panichi R, Wadiche JI, Overstreet Wadiche L (2013) Distinct determinants of sparse activation during granule cell maturation. J Neurosci 33:19131-19142. 
Drew LJ, Kheirbek MA, Luna VM, Denny CA, Cloidt MA, Wu MV, Jain S, Scharfman HE, Hen R (2015) Activation of local inhibitory circuits in the dentate gyrus by adult-born neurons. Hippocampus 26:763-778.

Engel D, Jonas P (2005) Presynaptic action potential amplification by voltage-gated $\mathrm{Na}+$ channels in hippocampal mossy fiber boutons. Neuron 45:405-417.

Epp JR, Spritzer MD, Galea LAM (2007) Hippocampus-dependent learning promotes survival of new neurons in the dentate gyrus at a specific time during cell maturation. Neuroscience 149:273-285.

Faulkner RL, Jang M-H, Liu X-B, Duan X, Sailor KA, Kim JY, Ge S, Jones EG, Ming G-L, Song H, Cheng H-J (2008) Development of hippocampal mossy fiber synaptic outputs by new neurons in the adult brain. Proc Natl Acad Sci U S A 105:14157-14162.

Feldman LA, Shapiro ML, Nalbantoglu J (2010) A novel, rapidly acquired and persistent spatial memory task that induces immediate early gene expression. Behav Brain Funct 6:35.

Flood DG, Buell SJ, Defiore CH, Horwitz GJ, Coleman PD (1985) Agerelated dendritic growth in dentate gyrus of human brain is followed by regression in the "oldest old". Brain Res 345:366-368.

Flor-García M, Terreros-Roncal J, Moreno-Jiménez EP, Ávila J, Rábano A, Llorens-Martín M (2020) Unraveling human adult hippocampal neurogenesis. Nat Protoc 15:668-693.

Galimberti I, Gogolla N, Alberi S, Santos AF, Muller D, Caroni P (2006) Long-term rearrangements of hippocampal mossy fiber terminal connectivity in the adult regulated by experience. Neuron 50:749-763.

Galimberti I, Bednarek E, Donato F, Caroni P (2010) EphA4 signaling in juveniles establishes topographic specificity of structural plasticity in the hippocampus. Neuron 65:627-642.

Ge S, Yang C-H, Hsu K-S, Ming G-L, Song H (2007) A critical period for enhanced synaptic plasticity in newly generated neurons of the adult brain. Neuron 54:559-566.

Geinisman Y, de Toledo-Morrell L, Morrell F (1986) Loss of perforated synapses in the dentate gyrus: morphological substrate of memory deficit in aged rats. Proc Natl Acad Sci U S A 83:3027-3031.

Gonçalves JT, Bloyd CW, Shtrahman M, Johnston ST, Schafer ST, Parylak SL, Tran T, Chang T, Gage FH (2016) In vivo imaging of dendritic pruning in dentate granule cells. Nat Neurosci 19:788-791.

Gu Y, Arruda-Carvalho M, Wang J, Janoschka SR, Josselyn SA, Frankland PW, Ge S (2012) Optical controlling reveals time-dependent roles for adult-born dentate granule cells. Nat Neurosci 15:1700-1706.

Guo N, Soden ME, Herber C, Kim MT, Besnard A, Lin P, Ma X, Cepko CL, Zweifel LS, Sahay A (2018) Dentate granule cell recruitment of feedforward inhibition governs engram maintenance and remote memory generalization. Nat Med 24:438-449.

Henze DA, Wittner L, Buzsáki G (2002) Single granule cells reliably discharge targets in the hippocampal CA3 network in vivo. Nat Neurosci 5:790-795.

Holtmaat A, Svoboda K (2009) Experience-dependent structural synaptic plasticity in the mammalian brain. Nat Rev Neurosci 10:647-658.

Imura T, Kobayashi Y, Suzutani K, Ichikawa-Tomikawa N, Chiba H (2018) Differential expression of a stress-regulated gene Nr4a2 characterizes early- and late-born hippocampal granule cells. Hippocampus 29:539549 .

Jessberger S, Zhao C, Toni N, Clemenson GD, Li Y, Gage FH (2007) Seizureassociated, aberrant neurogenesis in adult rats characterized with retrovirus-mediated cell labeling. J Neurosci 27:9400-9407.

Jungenitz $\mathrm{T}$, Beining $\mathrm{M}$, Radic $\mathrm{T}$, Deller $\mathrm{T}$, Cuntz $\mathrm{H}$, Jedlicka $\mathrm{P}$, Schwarzacher SW (2018) Structural homo- and heterosynaptic plasticity in mature and adult newborn rat hippocampal granule cells. Proc Natl Acad Sci U S A 115:E4670-E4679.

Kempermann G (2008) The neurogenic reserve hypothesis: what is adult hippocampal neurogenesis good for? Trends Neurosci 31:163-169.

Kempermann G, Gage FH, Aigner L, Song H, Curtis MA, Thuret S, Kuhn HG, Jessberger S, Frankland PW, Cameron HA, Gould E, Hen R, Abrous DN, Toni N, Schinder AF, Zhao X, Lucassen PJ, Frisén J (2018) Human adult neurogenesis: evidence and remaining questions. Cell Stem Cell 23:25-30.

Kerloch T, Clavreul S, Goron A, Abrous DN, Pacary E (2019) Dentate granule neurons generated during perinatal life display distinct morphological features compared with later-born neurons in the mouse hippocampus. Cereb Cortex 29:3527-3539.
Kim WR, Christian K, Ming G-L, Song H (2012) Time-dependent involvement of adult-born dentate granule cells in behavior. Behav Brain Res 227:470-479.

Kirn JR, Alvarez-Buylla A, Nottebohm F (1991) Production and survival of projection neurons in a forebrain vocal center of adult male canaries. The Journal of neuroscience: the official journal of the Society for Neuroscience 11:1756-1762.

Kohler SJ, Williams NI, Stanton GB, Cameron JL, Greenough WT (2011) Maturation time of new granule cells in the dentate gyrus of adult macaque monkeys exceeds six months. Proc Natl Acad Sci U S A 108:1032610331.

Kole MHP, Ilschner SU, Kampa BM, Williams SR, Ruben PC, Stuart GJ (2008) Action potential generation requires a high sodium channel density in the axon initial segment. Nat Neurosci 11:178-186.

Kuhn HG, Dickinson-Anson H, Gage FH (1996) Neurogenesis in the dentate gyrus of the adult rat: age-related decrease of neuronal progenitor proliferation. J Neurosci 16:2027-2033.

Laplagne DA, Espósito MS, Piatti VC, Morgenstern NA, Zhao C, van Praag H, Gage FH, Schinder AF (2006) Functional convergence of neurons generated in the developing and adult hippocampus. PLoS Biol 4:e409.

Lazic SE (2012) Modeling hippocampal neurogenesis across the lifespan in seven species. Neurobiol Aging 33:1664-1671.

Leal SL, Yassa MA (2015) Neurocognitive aging and the hippocampus across species. Trends Neurosci 38:800-812.

Lemaire V, Tronel S, Montaron M-F, Fabre A, Dugast E, Abrous DN (2012) Long-lasting plasticity of hippocampal adult-born neurons. J Neurosci 32:3101-3108

Leslie AT, Akers KG, Krakowski AD, Stone SSD, Sakaguchi M, ArrudaCarvalho M, Frankland PW (2011) Impact of early adverse experience on complexity of adult-generated neurons. Translational psychiatry 1:e35.

Leranth C, Hajszan T (2007) Extrinsic afferent systems to the dentate gyrus. Prog Brain Res 163:63-84.

Llorens-Martín M, Jurado-Arjona J, Fuster-Matanzo A, Hernández F, Rábano A, Ávila J (2014) Peripherally triggered and GSK-3 $\beta$-driven brain inflammation differentially skew adult hippocampal neurogenesis, behavioral pattern separation and microglial activation in response to ibuprofen. Transl Psychiatry 4:e463.

Llorens-Martín M, Jurado-Arjona J, Bolós M, Pallas-Bazarra N, Ávila J (2016) Forced swimming sabotages the morphological and synaptic maturation of newborn granule neurons and triggers a unique pro-inflammatory milieu in the hippocampus. Brain Behav Immun 53:242-254.

Longair MH, Baker DA, Armstrong JD (2011) Simple Neurite Tracer: open source software for reconstruction, visualization and analysis of neuronal processes. Bioinformatics 27:2453-2454.

Losonczy A, Makara JK, Magee JC (2008) Compartmentalized dendritic plasticity and input feature storage in neurons. Nature 452:436-441.

Marín-Burgin A, Mongiat LA, Pardi MB, Schinder AF (2012) Unique processing during a period of high excitation/inhibition balance in adult-born neurons. Science 335:1238-1242.

Mathon B, Nassar M, Simonnet J, Le Duigou C, Clemenceau S, Miles R, Fricker D (2015) Increasing the effectiveness of intracerebral injections in adult and neonatal mice: a neurosurgical point of view. Neurosci Bull 31:685-696.

Mongiat LA, Espósito MS, Lombardi G, Schinder AF (2009) Reliable activation of immature neurons in the adult hippocampus. PLoS One 4:e5320.

Moreno-Jiménez EP, Flor-García M, Terreros-Roncal J, Rábano A, Cafini F, Pallas-Bazarra N, Avila J, Llorens-Martín M (2019) Adult hippocampal neurogenesis is abundant in neurologically healthy subjects and drops sharply in patients with Alzheimer's disease. Nature Publishing Group 108:621.

Niibori Y, Yu T-S, Epp JR, Akers KG, Josselyn SA, Frankland PW (2012) Suppression of adult neurogenesis impairs population coding of similar contexts in hippocampal CA3 region. Nat Comm 3:1253.

Ofer N, Shefi O, Yaari G (2017) Branching morphology determines signal propagation dynamics in neurons. Sci Rep 7:8877.

Ohkawa N, Saitoh Y, Tokunaga E, Nihonmatsu I, Ozawa F, Murayama A, Shibata F, Kitamura T, Inokuchi K (2012) Spine formation pattern of adult-born neurons is differentially modulated by the induction timing and location of hippocampal plasticity. PLoS One 7:e45270.

Ohline SM, Wake KL, Hawkridge M-V, Dinnunhan MF, Hegemann RU, Wilson A, Schoderboeck L, Logan BJ, Jungenitz T, Schwarzacher SW, Hughes SM, Abraham WC (2018) Adult-born dentate granule cell 
excitability depends on the interaction of neuron age, ontogenetic age and experience. Brain Struct Funct 223:3213-3228.

Overstreet-Wadiche LS, Bensen AL, Westbrook GL (2006) Delayed development of adult-generated granule cells in dentate gyrus. J Neurosci 26:2326-2334.

Paredes MF, Sorrells SF, Cebrian-Silla A, Sandoval K, Qi D, Kelley KW, James D, Mayer S, Chang J, Auguste KI, Chang EF, Martin AJG, Kriegstein AR, Mathern GW, Oldham MC, Huang EJ, Garcia-Verdugo JM, Yang Z, Alvarez-Buylla A (2018) Does adult neurogenesis persist in the human hippocampus? Cell Stem Cell 23:780-781.

Piatti VC, Davies-Sala MG, Espósito MS, Mongiat LA, Trinchero MF, Schinder AF (2011) The timing for neuronal maturation in the adult hippocampus is modulated by local network activity. The Journal of neuroscience: the official journal of the Society for Neuroscience 31:7715-7728.

Radic T, Al-Qaisi O, Jungenitz T, Beining M, Schwarzacher SW (2015) Differential Structural Development of Adult-Born Septal Hippocampal Granule Cells in the Thy1-GFP Mouse, Nuclear Size as a New Index of Maturation. PLoS ONE 10:e0135493.

Restivo L, Niibori Y, Mercaldo V, Josselyn SA, Frankland PW (2015) Development of adult-generated cell connectivity with excitatory and inhibitory cell populations in the hippocampus. J Neurosci 35:1060010612.

Rollenhagen A, Sätzler K, Rodríguez EP, Jonas P, Frotscher M, Lübke JHR (2007) Structural determinants of transmission at large hippocampal mossy fiber synapses. J Neurosci 27:10434-10444.

Rolls ET (2010) A computational theory of episodic memory formation in the hippocampus. Behav Brain Res 215:180-196.

Rowan MJM, DelCanto G, Yu JJ, Kamasawa N, Christie JM (2016) Synapselevel determination of action potential duration by $\mathrm{k}+$ channel clustering in axons. Neuron 91:370-383.

Ruediger S, Vittori C, Bednarek E, Genoud C, Strata P, Sacchetti B, Caroni P (2011) Learning-related feedforward inhibitory connectivity growth required for memory precision. Nature 473:514-518.

Save L, Baude A, Cossart R (2019) Temporal embryonic origin critically determines cellular physiology in the dentate gyrus. Cereb Cortex 29:2639-2652.

Schlessinger AR, Cowan WM, Gottlieb DI (1975) An autoradiographic study of the time of origin and the pattern of granule cell migration in the dentate gyrus of the rat. J Comp Neurol 159:149-175.

Schmidt-Hieber C, Jonas P, Bischofberger J (2004) Enhanced synaptic plasticity in newly generated granule cells of the adult hippocampus. Nature 429:184-187.

Seress L (1992) Morphological variability and developmental aspects of monkey and human granule cells: differences between the rodent and primate dentate gyrus. Epilepsy Res Suppl 7:3-28.

Seress L, Frotscher M (1990) Morphological variability is a characteristic feature of granule cells in the primate fascia dentata: a combined Golgi/electron microscope study. J Comp Neurol 293:253-267.

Shapiro LA, Upadhyaya P, Ribak CE (2007) Spatiotemporal profile of dendritic outgrowth from newly born granule cells in the adult rat dentate gyrus. Brain research 1149:30-37.

Small SA, Chawla MK, Buonocore M, Rapp PR, Barnes CA (2004) Imaging correlates of brain function in monkeys and rats isolates a hippocampal subregion differentially vulnerable to aging. Proc Natl Acad Sci U S A 101:7181-7186.

Snyder JS (2019) Recalibrating the relevance of adult neurogenesis. Trends Neurosci 42:164-178

Snyder JS, Cameron HA (2012) Could adult hippocampal neurogenesis be relevant for human behavior? Behav Brain Res 227:384-390.

Snyder JS, Kee N, Wojtowicz JM (2001) Effects of adult neurogenesis on synaptic plasticity in the rat dentate gyrus. J Neurophysiol 85:2423-2431.

Snyder JS, Choe JS, Clifford MA, Jeurling SI, Hurley P, Brown A, Kamhi JF, Cameron HA (2009) Adult-born hippocampal neurons are more numerous, faster maturing, and more involved in behavior in rats than in mice. J Neurosci 29:14484-14495.

Spruston N (2008) Pyramidal neurons: dendritic structure and synaptic integration. Nat Rev Neurosci 9:206-221.

Stone SSD, Teixeira CM, Zaslavsky K, Wheeler AL, Martinez-Canabal A, Wang AH, Sakaguchi M, Lozano AM, Frankland PW (2011) Functional convergence of developmentally and adult-generated granule cells in dentate gyrus circuits supporting hippocampus-dependent memory. Hippocampus 21:1348-1362.

Sun GJ, Sailor KA, Mahmood QA, Chavali N, Christian KM, Song H, Ming G-L (2013) Seamless reconstruction of intact adult-born neurons by serial end-block imaging reveals complex axonal guidance and development in the adult hippocampus. The Journal of neuroscience: the official journal of the Society for Neuroscience 33:11400-11411.

Tashiro A, Makino H, Gage FH (2007) Experience-specific functional modification of the dentate gyrus through adult neurogenesis: a critical period during an immature stage. The Journal of neuroscience: the official journal of the Society for Neuroscience 27:3252-3259.

Toni N, Teng EM, Bushong EA, Aimone JB, Zhao C, Consiglio A, van Praag H, Martone ME, Ellisman MH, Gage FH (2007) Synapse formation on neurons born in the adult hippocampus. Nat Neurosci 10:727-734

Toni N, Laplagne DA, Zhao C, Lombardi G, Ribak CE, Gage FH, Schinder AF (2008) Neurons born in the adult dentate gyrus form functional synapses with target cells. Nat Neurosci 11:901-907.

Trinchero MF, Buttner KA, Sulkes Cuevas JN, Temprana SG, Fontanet PA, Monzón-Salinas MC, Ledda F, Paratcha G, Schinder AF (2017) High plasticity of new granule cells in the aging hippocampus. Cell Rep 21:1129-1139.

Tronel S, Fabre A, Charrier V, Oliet SHR, Gage FH, Abrous DN (2010) Spatial learning sculpts the dendritic arbor of adult-born hippocampal neurons. Proc Natl Acad Sci U S A 107:7963-7968.

Tronel S, Lemaire V, Charrier V, Montaron M-F, Abrous DN (2015) Influence of ontogenetic age on the role of dentate granule neurons. Brain Struct Funct 220:645-661.

van Praag H, Schinder AF, Christie BR, Toni N, Palmer TD, Gage FH (2002) Functional neurogenesis in the adult hippocampus. Nature 415:10301034.

Villasana LE, Kim KN, Westbrook GL, Schnell E (2015) Functional integration of adult-born hippocampal neurons after traumatic brain injury. eNeuro 2:ENEURO.0056-15.2015.

Vivar C, Peterson BD, Praag H van (2015) Running rewires the neuronal network of adult-born dentate granule cells. NeuroImage 131:29-41.

Vyleta NP, Borges-Merjane C, Jonas P (2016) Plasticity-dependent, full detonation at hippocampal mossy fiber-CA3 pyramidal neuron synapses. Elife 5:e17977.

Wang J-W, David DJ, Monckton JE, Battaglia F, Hen R (2008) Chronic fluoxetine stimulates maturation and synaptic plasticity of adult-born hippocampal granule cells. The Journal of neuroscience: the official journal of the Society for Neuroscience 28:1374-1384.

Wang S, Scott BW, Wojtowicz JM (2000) Heterogenous properties of dentate granule neurons in the adult rat. J Neurobiol 42:248-257.

West MJ, Slomianka L, Gundersen HJ (1991) Unbiased stereological estimation of the total number of neurons in thesubdivisions of the rat hippocampus using the optical fractionator. Anat Rec 231:482-497.

Williams RS, Matthysse S (1983) Morphometric analysis of granule cell dendrites in the mouse dentate gyrus. J Comp Neurol 215:154-164.

Witter MP (2007) The perforant path: projections from the entorhinal cortex to the dentate gyrus. Prog Brain Res 163:43-61.

Yassa MA, Muftuler LT, Stark CEL (2010) Ultrahigh-resolution microstructural diffusion tensor imaging reveals perforant path degradation in aged humans in vivo. Proc Natl Acad Sci U S A 107:12687-12691.

Zhao C, Teng EM, Summers RG, Ming G-L, Gage FH (2006) Distinct morphological stages of dentate granule neuron maturation in the adult mouse hippocampus. J Neurosci 26:3-11. 